\title{
Breast implant-associated anaplastic large cell lymphoma: a review
}

\author{
Andrés E. Quesada ${ }^{1} \cdot$ L. Jeffrey Medeiros ${ }^{1} \cdot$ Mark W. Clemens $^{2} \cdot$ Maria C. Ferrufino-Schmidt $^{3} \cdot$ Sergio Pina-Oviedo $^{4}$. \\ Roberto N. Miranda ${ }^{1}$
}

Received: 29 March 2018 / Revised: 31 May 2018 / Accepted: 2 June 2018 / Published online: 11 September 2018

(c) United States \& Canadian Academy of Pathology 2018

\begin{abstract}
Breast implant-associated anaplastic large cell lymphoma is a newly recognized provisional entity in the 2017 revision of the World Health Organization Classification of Tumors of Hematopoietic and Lymphoid Tissues. It is an uncommon, slow growing T-cell lymphoma with morphology and immunophenotype similar to anaplastic lymphoma kinase-negative anaplastic large cell lymphoma. However, the presentation and treatment are unique. Breast implant-associated anaplastic large cell lymphoma often presents as a unilateral effusion confined to the capsule of a textured-surface breast implant, a median time of 9 years after the initial implants have been placed. Although it follows an indolent clinical course, breast implant-associated anaplastic large cell lymphoma has the potential to form a mass, to invade locally through the capsule into breast parenchyma or soft tissue and/or to spread to regional lymph nodes. In most cases, an explantation with a complete capsulectomy removing all disease, without chemotherapy is considered to be curative and confers an excellent event free and overall survival. Here we provide a comprehensive review of breast implant-associated anaplastic large cell lymphoma, including history, epidemiology, clinical features, imaging and pathology findings, pathologic handling, pathogenic mechanisms, model for progression, therapy and outcomes as well as an analysis of causality between breast implants and anaplastic large cell lymphoma.
\end{abstract}

\section{Introduction}

Breast implant-associated anaplastic large cell lymphoma (breast implant ALCL) is a rare type of non-Hodgkin lymphoma that is likely under-recognized and underreported. In 1997, Keech and Creech first called attention to breast implant ALCL when they described a case of anaplastic large cell lymphoma in association with silicone breast implants [1]. However, the association between implants and ALCL did not garner much attention until 2008 when Roden et al. described four patients with a CD30-positive T-cell lymphoproliferative disorder

Roberto N. Miranda

Roberto.miranda@mdanderson.org

1 Department of Hematopathology, The University of Texas MD Anderson Cancer Center, Houston, TX, USA

2 Department of Plastic Surgery, The University of Texas MD Anderson Cancer Center, Houston, TX, USA

3 Universidad Peruana de Ciencias Aplicadas, Lima, Peru

4 Department of Pathology and Laboratory Services, University of Arkansas for Medical Sciences, Little Rock, AR, USA surrounding breast implants which they designated as seroma-associated primary anaplastic large cell lymphoma [2]. Since that time, evidence has accumulated showing that breast implant ALCL is a unique clinicopathologic entity that requires unique management and therapeutic approaches. In 2017, breast implant ALCL was incorporated as a provisional entity in the revised fourth edition of the World Health Organization classification of lymphomas [3].

In this review, we discuss the epidemiology, clinicopathologic features, imaging findings, model for progression, therapeutic approach and outcomes for patients with breast implant ALCL. We also summarize the pathogenic mechanisms, and provide an analysis of factors that support a causal relationship between breast implants and ALCL.

\section{Overview and history of breast implants}

Approximately 450,000 breast implants are placed annually for reconstructive or cosmetic purposes in the United States [4]. As of 2010, it was estimated that 5,083,717 (4.93\%) women in the United States had breast implants. Most women are between the ages of 30 and 39 years, and the 
average patient age at the time of implant placement is 34 years [5]. Globally, it is estimated that at least 10 million women have breast implants [4].

The history of breast reconstruction and cosmetic augmentation is over 100 years old. A variety of implant fillers have been used over the years, but silicone breast implants were used initially in 1962 [6]. The United States Food and Drug Administration (FDA) allowed these devices to stay on the market with the enactment of the 1976 Medical Device Amendments to the Food, Drug and Cosmetic Act [7, 8]. Although implants were approved by the FDA, manufacturers were nonetheless required to submit data showing the safety of breast implants. Shortly thereafter, a crisis of health concerns followed, particularly regarding a potential etiologic relationship between breast implants and rheumatologic and connective tissue-related diseases [916]. Due to insufficient evidence demonstrating the safety of implants, on April 16, 1992 the FDA announced that breast implants filled with silicone gel would be available only for reconstructive surgery through controlled clinical studies [7]. Saline-filled implants would remain on the market. Epidemiological data and analysis over subsequent years failed to disclose a causal relationship between breast implants and connective tissue or autoimmune disorders [17-20]. However, a variety of local complications, including inflammation and granulomas, were noted. These findings were in line with animal studies that showed silicone-induced inflammatory changes and that silicone could migrate from the injection site to various organs including lymph nodes, spleen and lungs $[6,21]$.

In 1998, the FDA issued its first release on the risk of breast implants, stating that a pathogenetic relationship between these devices and rheumatic disease had been excluded [4]. However, this release did not address any potential association of breast implants with carcinoma or lymphoma. After a 15-year moratorium, the FDA granted approval for saline breast implants in 2000 and for siliconefilled breast implants in 2006. A mounting number of case reports of ALCL associated with breast implants led the FDA to issue a safety warning on the possible association between breast implants and ALCL in 2011 [4]. Due to the increasing awareness of these neoplasms, it has recently been proposed that preoperative informed consent for breast implant surgery should include informing the patient about the risk of developing breast implant ALCL [22].

\section{Structure of breast implants}

Breast implants consist of an outer silicone shell that is filled with either saline or silicone gel. Once implants are in place, the physiologic reaction is the formation of a collagen-rich fibrous encasement around the implant, also known as the capsule [23]. A known complication of implants is capsular contracture in which the fibrous capsule tightens causing the breast to feel indurated, hardened and/ or painful, along with an appearance that is cosmetically unacceptable [24]. The median life of an implant is approximately 16 years, and rupture can occur at a rate of $2-3 \%$ per year. A minimal (so-called "sweat") migration of silicone material also can slip through surrounding fibrous tissue or to regional lymph nodes, causing a histiocytic reaction, although usually minimal. A more substantial histiocytic and foreign body-type giant cell reaction and fibrosis usually results from ruptured implants, and silicone can permeate through the surrounding soft tissue, sometimes forming large fibrohistiocytic aggregates admixed with silicone material or masses known as "siliconomas", either in surrounding soft tissues or lymph nodes.

The outer shell of an implant can be either smooth or textured, and there are differences in their make and synthesis according to manufacturers. When silicone implants were first introduced in the 1960s, they had a smooth outer surface with a roughened dacron patch (polyethylene terephthalate) on the posterior side to prevent migration [20]. In the 1970 s, a rough polyurethane coat was added which stimulated tissue ingrowth into the surface of the device. Textured silicone-surface implants were introduced in 1987 and have a rough and irregular surface accomplished by abrading the surface with salt, chemicals, or negative imprint stamping techniques. The textured surface is designed to minimize implant movement within the breast as well as potentially reduce the complication of capsular contracture [20]. Prospective studies, however, have shown no difference in the rate of capsular contraction in the majority of patients with textured as compared with smooth implants [25]. Smooth implants are presently used by the vast majority of plastic surgeons in the United States and Canada, whereas textured surface implants are preferred in South America, Asia, Europe and Oceania. The fibrous capsule is usually attached tightly to the surface of the implant shell; occasionally there is a virtual space, in which a minimal amount of fluid collects; in this latter circumstance the capsule develops a synovium-like lining layer. Uncomplicated fibrous capsules are usually less than 500 $\mu \mathrm{m}$ in thickness and are mostly devoid of inflammatory cells.

\section{Epidemiology}

Lymphomas involving the breast account for approximately $2 \%$ of all extranodal lymphomas and less than $1 \%$ of all non-Hodgkin lymphomas [26]. Most lymphomas that involve the breasts are of B-cell lineage, with diffuse large cell B-cell lymphoma and extranodal marginal zone 
Table 1 Timeline of landmark studies on breast implant-associated anaplastic large cell lymphoma

\begin{tabular}{lll}
\hline Year & Reference & Contribution \\
\hline 1997 & Keech JA and Creech BJ [1] & First reported case breast implant ALCL \\
2008 & Roden A et al. [2] & Suggests that breast implant ALCL is a unique entity with indolent clinical course \\
2008 & De Jong D et al. [27] & Increased risk of ALCL in patients with breast implants in case control study \\
2011 & .Carty MJ et al. [28] & First death attributed to breast implant ALCL \\
2012 & Talwalkar S et al. [26] & 3 of 106 patients with breast lymphomas associated with breast implants \\
2012 & Aladily T et al. [29] & Pathologic spectrum of breast implant ALCL reveals prognostic value of cases with tumor mass \\
2012 & Lechner M et al. [30] & Cell lines used to characterize activating survival signaling pathways \\
2014 & Miranda RN et al. [31] & Long-term follow-up revealed excellent prognosis for patients with disease confined to capsule \\
& & Chemotherapy may not be indicated for all patients with breast implant ALCL \\
2014 & Adrada BE et al. [32] & Breast implant ALCL analyzed with different modalities revealed variable sensitivity and specificity of \\
& & imaging studies \\
2016 & Hu H et al. [33] & Ralstonia spp identified in biofilm of capsules of affected patients \\
2016 & Clemens MW et al. [34] & Definitive therapy requires complete surgical excision of tumor \\
2016 & Wang SS et al. [35] & Increased risk of ALCL in patients with breast implants in cohort study \\
2017 & Doren EL et al. [36] & Texturing of implants associated with increased risk of breast implant ALCL \\
2018 & De Boer M et al. [37] & Estimated that 1 in 6920 women with implants develops breast implant ALCL \\
2018 & Oishi N et al. [38] & JAK1 and STAT3 mutations, but no DUSP22 or P63 rearrangements noted in breast implant ALCL \\
\hline
\end{tabular}

Breast implant ALCL Breast implant-associated anaplastic large cell lymphoma

lymphoma of mucosa associated lymphoid tissue being most common [26]. Anaplastic large cell lymphoma is an uncommon T-cell neoplasm that accounts for approximately $3 \%$ of non-Hodgkin lymphomas. In a series of 106 cases, Talwalkar et al. reported that cases of ALCL accounted for $6 \%$ of all lymphomas involving the breast, and three cases in that study were associated with breast implants [26]. These data suggested that ALCL and breast implants were associated. A timetable of landmark studies on breast implant ALCL is shown in Table 1 [1, 2, 26-38].

De Jong et al. [27] conducted a case control study in The Netherlands that included 389 women with non-Hodgkin lymphoma in the breast over a 16-year span; five cases of ALCL were identified in patients with breast implants, and 6 other patients with ALCL lacked implants. For each of these 11 patients, the authors selected 1-5 controls with other lymphomas of the breast, matched to age and year of diagnosis. The calculated odds ratio was 18.2 (95\% confidence interval, 2.1-156.8) indicating that patients with breast ALCL are significantly more likely to have breast implants [27]. DeJong et al. in 2008 estimated that the incidence of breast implant ALCL in The Netherlands was of approximately of 1-3 per million per year [27, 29, 39].

Lipworth et al. examined five long-term studies with clinical follow-up as long as 37 years. A total of 48 lymphomas in 43,000 women with implants were found compared to an expected 54 lymphoma cases [40]. More recently, Largent et al. reviewed prospectively six clinical studies sponsored by a breast implant manufacturer and they reported 28 lymphomas in 89,382 women with implants, compared to 43 expected lymphomas over a median follow-up of only 2.7 years [41]. Both reports concluded that the incidence of ALCL was not increased in patients with implants; however, neither study is conclusive. The first study included a relatively small number of women and none of the lymphomas were in the breast, suggesting under-reporting. The second study had a short period of observation at 2.7 years, inadequate when one considers that the median time from implantation to diagnosis of breast implant ALCL is 9 years.

Wang et al. [35]. utilized a database of 123,392 women from the California Teachers Study cohort to identify 2990 women with breast implants. They conducted a prospective study to evaluate the association between breast implants and T-cell lymphoma. Of 89 women who developed T-cell lymphoma, only two patients developed ALCL; these two patients had breast implants. Nevertheless, these cases are illustrative. Although the hazard ratio calculation showed no association between breast implants and T-cell lymphoma overall, a statistically significant association was seen for breast implants and ALCL. Furthermore, they found a 10.9 times increased risk specific for ALCL in patients who reported a history of breast implants at the study baseline [35]. With this growing epidemiological data, as well as strong clinical and pathological evidence, there is apparent substantial support for a pathogenic relationship. Furthermore, the epidemiological data are likely hampered by underdiagnosis and misdiagnosis of breast implant ALCL by imaging and/or histopathology [42]. De Boer et al. in 2018 estimated that the number of women 

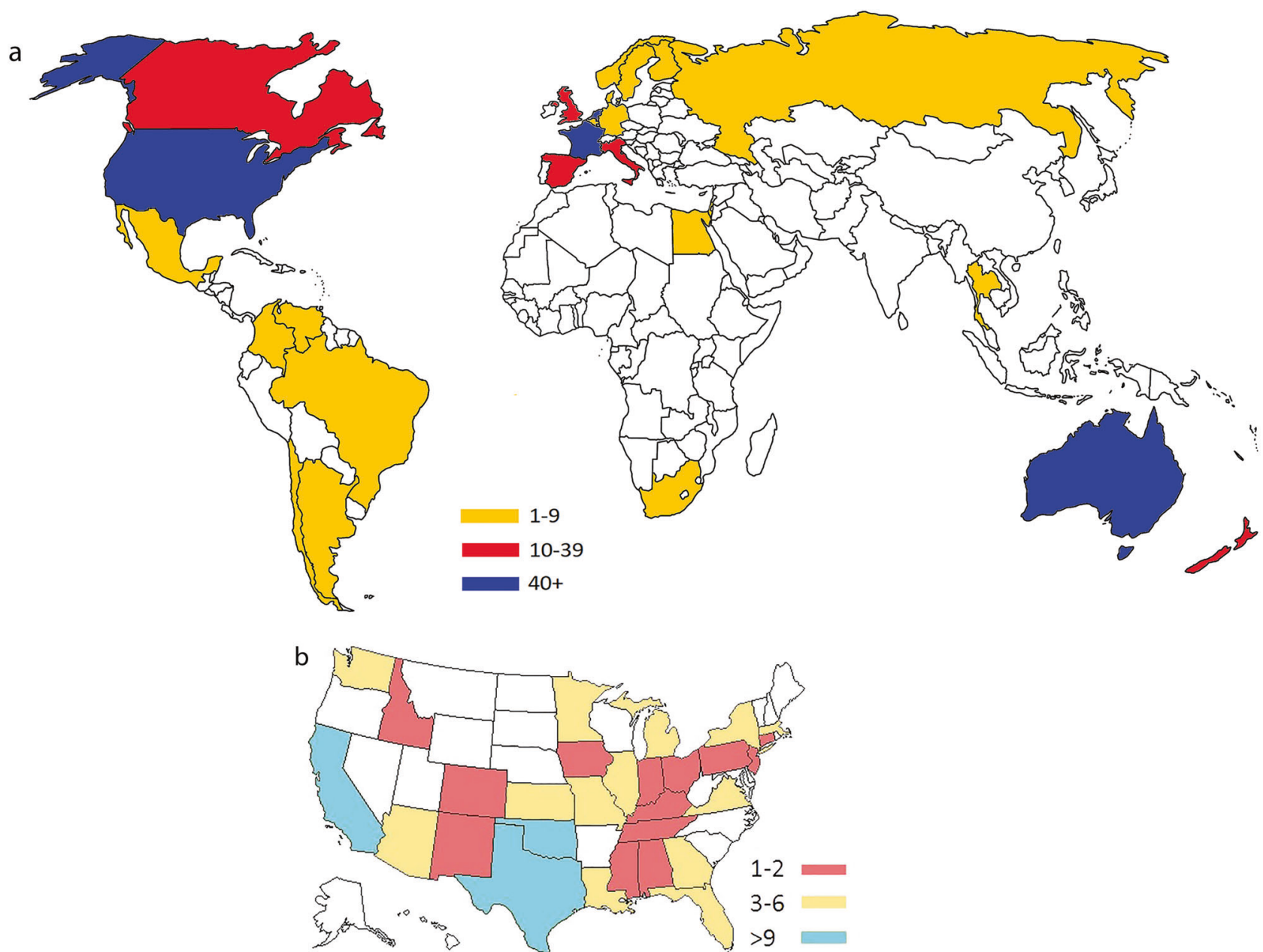

Fig. 1 Geographic distribution of patients diagnosed with breast implant-associated anaplastic large cell lymphoma (breast implant ALCL). a Worldwide distribution of 561 cases reported in 29 countries. b United States distribution of 123 cases reported in 31 states. The range of reported cases per country or state is shown in the insets with implants needed to identify one breast implant ALCL case before age 75 years was 6920 [37].

Doren et al. [36]. analyzed cases of breast implant ALCL in the United States and found that information regarding texturing of implants was available in approximately $50 \%$ of all cases. For bona fide cases of breast implant ALCL, all patients had a history of textured implants. Importantly, Doren et al. [36]. estimated that the prevalence of breast implant ALCL among patients with textured implants is 1 in 30,000 women, and the risk of breast implant ALCL is increased by nearly 70 fold in patients with textured implants when compared with all women in the general population and with smooth implants. De Boer et al. also found an increase proportion of breast implant ALCL among patients with textured implants [37]. If these findings are confirmed, there is hope that reimplantation with smooth implants may be an alternative for women with breast implant ALCL wishing to continue to have breast implants.
A release of the U.S. Food \& Drug Administration in March 2018 referred that out of 272 cases with details of the surface, 242 were textured, while 30 were smooth [43]. However, it is important to note that some patients received multiple implant replacements before a diagnosis of breast implant ALCL was rendered, and retrieval of information on the surface of the implant was not definitive.

As of July 1, 2018, 561 cases of breast implant ALCL across 29 countries worldwide have been reported, which includes 226 United States cases known to the PROFILE (Patient Registry and Outcomes for Breast Implants and ALCL Etiology and Epidemiology) patient registry[5, 39, 44, 45].(Fig. 1a) We believe the frequency of this neoplasm is likely underreported and presently limited mainly to cases in the United States, Europe and Australia. Within the United States, data for states was available for 123 cases reported in 31 states, with most cases diagnosed in Texas, California, and Florida. (Fig. 1b) The U.S. Food and Drug 
Administration released a statement on March 21, 2018 [43] reporting 414 cases of breast implant ALCL as of September 30, 2017. The report also states that the lifetime risk for breast implant ALCL is between 1 in 3,817 and 1 in 30,000 women with textured breast implants [43].

\section{Clinical features}

The most common clinical presentation of breast implant ALCL is an effusion around the implant, in about two thirds of patients. Although often referred to as a seroma, this designation is scientifically incorrect. A seroma should be a transudate, with a low cell count and low protein content. In contrast, in a patient with breast implant ALCL the effusion around the implant contains liquefied and necrotic lymphoma cells with a high protein content [31]. Approximately $30 \%$ of patients with breast implant ALCL present with a tumor mass, with or without effusion, usually felt by the patient as an indurated area with progressive growth along the medial or lateral surfaces of the implant [31, 34]. Approximately $20 \%$ of patients present with associated regional, usually axillary lymphadenopathy; less frequently, infraclavicular or supraclavicular lymph nodes can be enlarged [46]. A small subset of patients with breast implant ALCL complain of a painful breast and rarely patients complain of a skin rash or pruritus on the chest or breast area. Lastly, there are very few patients in whom breast implant ALCL was discovered incidentally, at the time of surgery for unrelated causes or in the contralateral breast of patients with breast implant ALCL undergoing implant removal; in these patients the effusion is minimal or absent and no gross tumor is identified [31, 47].

Using the traditional Ann Arbor staging system, 83\% of patients with breast implant ALCL have clinical stage I, $10 \%$ stage II, and $7 \%$ stage IV disease at initial diagnosis [31]. Among the cases, one patient had central nervous system involvement and three patients with bilateral disease were considered as stage IV disease. However, it is currently debatable whether bilateral breast implant ALCL truly represents stage IV disease (contralateral metastasis) or is better considered as stage I with two independent primary neoplasms, each with its own prognostic characteristics. We suggest that bilateral neoplasms confined to the luminal side of the capsule are better considered as bilateral stage I disease. In these bilateral cases, DNA isolation to attempt establishing clonal relationship between both sides may contribute to clarify this discussion. On the other hand, if one side is invasive through the capsule, with or without lymphadenopathy, the contralateral side may represent disseminated disease. If bilateral axillary lymph nodes are involved, stage IV disease seems likely [48].
In our series, among patients who develop breast implant ALCL, approximately $60 \%$ had implants for cosmetic reasons and $40 \%$ because they had breast cancer first and the implants were part of breast reconstruction [31]. While patients with breast cancer reconstruction are more likely to have regular follow-up post therapy, patients with cosmetic implants are less likely to have regular follow-up beyond the perioperative period. Thus, breast implant ALCL may be more likely detected at an earlier stage in patients who have had breast cancer and breast reconstruction compared with patients who had cosmetic breast implants. There are also very small subsets of patients who have had implants placed for hypoplasia of breast parenchyma or breast reconstruction after prophylactic mastectomy for familial breast cancer. Data on the risk of breast implant ALCL in these patients group are unknown.

The time interval from implantation to diagnosis of breast implant ALCL varies in different series, with a range from 2 years to as late as 32 years; the median interval is 8-9 years [31]. An analysis of cases with apparent early onset of breast implant ALCL shows that these patients had a history of recent implant exchange surgery because of recurrent effusions that were not pathologically evaluated, until finally the diagnosis of breast implant ALCL was established [34]. These neoplasms therefore likely had an earlier onset related to a prior implant than was reported. Alternatively, some patients underwent biopsy of the fibrous capsule or partial capsulectomy (with or without reimplantation) and were misdiagnosed as chronic inflammation, allergic reaction or infection; with recurrence of a tumor mass or involvement of regional lymph nodes before the diagnosis of breast implant ALCL was established. (manuscript in preparation)

Both saline and silicone-filled implants have been reported in association with breast implant ALCL without a statistical difference in frequency [31]. In some reports, the physical characteristics of the implant have been noted. Both textured implants and smooth-shell implants with a prior textured implant history have been associated with breast implant ALCL. Spear et al. and Brody et al. have suggested that the appearance of breast implant ALCL coincided with the introduction of textured silicone-surface implants in 1987 [39, 49, 50]. Doren et al. investigated whether bona fide cases of breast implant ALCL were associated with smooth implants [36]. No cases of breast implant ALCL among 51 affected patients with available data had smooth implants only. However, two patients had earlier surgical procedures because of effusion around breast implants, at which time textured implants were replaced by smooth implants, raising the possibility that breast implant ALCL was already present at the time of removal of the textured implant. Overall, these data suggest 
Fig. 2 Imaging of breast implant ALCL. a Computed tomography scan showing implant and surrounding effusion fluid but no mass lesion. b Computed tomography scan showing implant with large adjacent mass lesion. (c) Computed tomography scan showing implant and small adjacent mass lesion. d Positron emission tomography scan showing increased avidity of the adjacent mass lesion
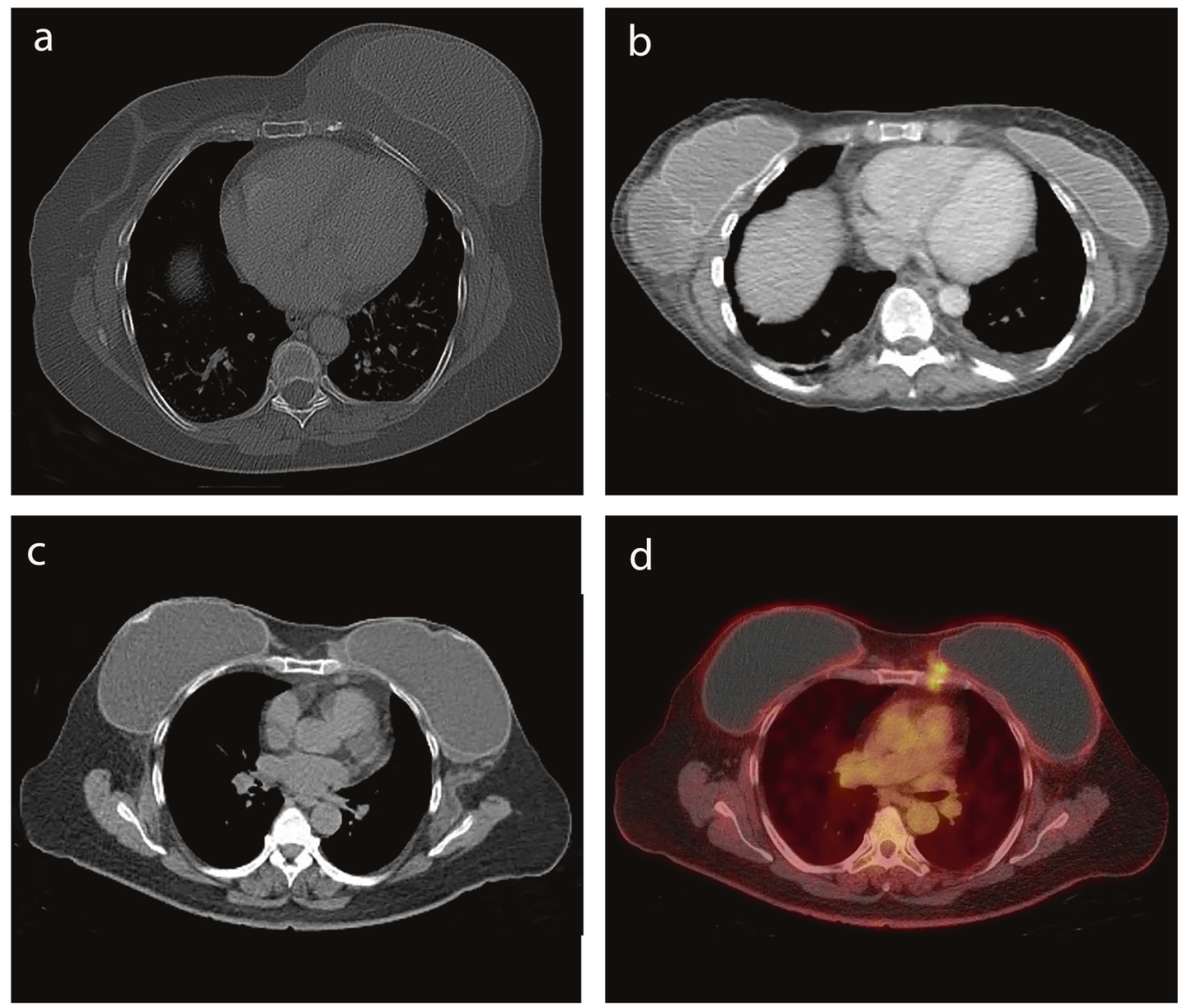

that textured breast implants are more likely to be associated with subsequent breast implant ALCL.

\section{Imaging studies}

Imaging studies of breast involved by breast implant ALCL usually show an effusion around the implant, with or without a distinct mass (Fig. 2a-d). Adrada et al. systematically studied the sensitivity and specificity of various imaging modalities for detecting breast implant ALCL [32]. In this retrospective study of 44 patients, the most sensitive procedure to detect effusion was ultrasound which achieved $84 \%$ sensitivity, and $75 \%$ specificity. Magnetic resonance imaging (MRI) had $82 \%$ sensitivity for detecting an effusion, and $50 \%$ specificity. Computed tomography (CT) scan and positron emission tomography (PET) scan studies had low sensitivity to detect effusions. In contrast, PET CT was most sensitive for detecting a tumor mass, whereas MRI was $50 \%$ sensitive and $93 \%$ specific. Mammography, although useful for screening of carcinoma of the breast, appeared to be poorly sensitive for detecting effusion around a breast implant, at about 30\%. Adrada et al. study was done at a time of incipient awareness of the disease by physicians of various specialties, thus, it is possible that an overall lack of awareness of breast implant ALCL may have led to under-recognition and underdiagnosis [32].

\section{Pathologic features}

\section{Capsules and implants negative for lymphoma}

Breast implants removed en bloc are encased by a fibrous capsule without masses or significant irregularities (Fig. 3a). The luminal side of the capsule is typically smooth and the overall thickness of the capsule is $<1 \mathrm{~mm}$ (Fig. 3b). Histologic examination shows synovium-like cells lining the luminal side of the capsule but otherwise show no or minimal inflammatory cells and no large or atypical cells (Fig. 3c) [47]. A CD30 stain performed on the capsule is negative, but on occasion there are rare positive small to intermediate in size cells in the stroma, but not clusters or aggregates of large cells in the luminal side (Fig. 3d).

\section{Gross findings}

The gross appearance of breast implant ALCL usually reflects the degree of infiltration by tumor cells. In patients with tumor cells confined to the luminal side of the capsule, the most remarkable feature is the presence of turbid 
Fig. 3 En bloc implant and capsule resection not involved by lymphoma. a Resected fibrous capsule overlying breast implant. No distortion and no masses noted on external examination. b Inner (luminal) surface of fibrous capsule with a smooth, tan appearance and no masses or irregularities. (c) Capsule synovium-like lining not involved by lymphoma; H\&E, 100x. d CD30 immunohistochemistry is negative in the lining cells; rare positive stromal cells highlighted by CD30, 400x
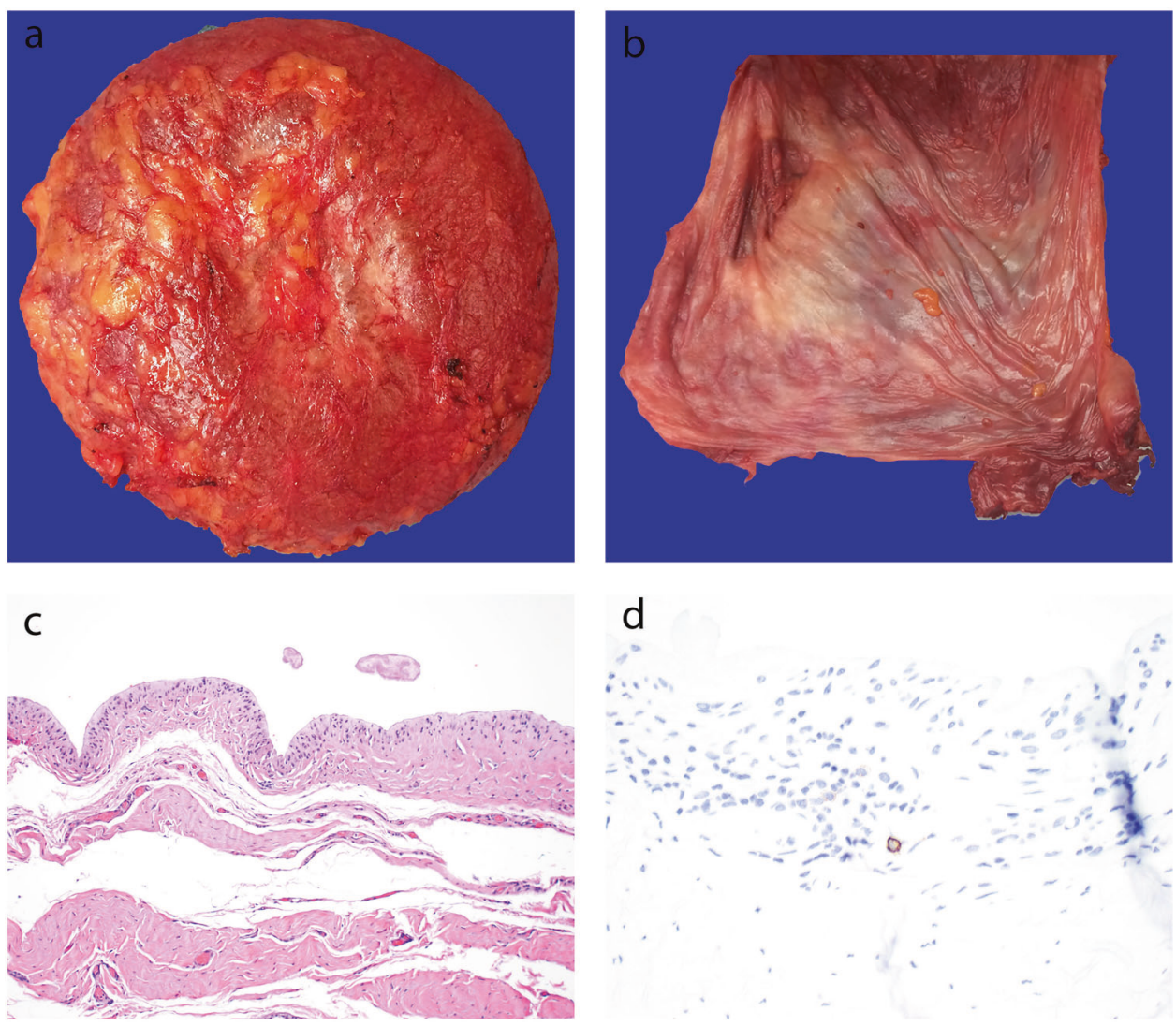

effusion accumulated in the space between the implant and the fibrous capsule (Fig. 4a). The volume of fluid can range from minimal to more than $500 \mathrm{~mL}[31,47]$. The capsule is usually membranous or slightly thickened and rubbery, likely related to contracture, and no distinct areas of tumor are noted. Upon opening the capsule is easily separated from the implant, but it may be attached to a portion of the implant, and the implant is usually intact. Sometimes, the only specimen pathologists receive are fragments of the capsule, particularly when the disease is not suspected and the surgeon samples randomly or identifies areas of induration in the capsule (Fig. 4b). If breast implant ALCL is suspected preoperatively, a surgical oncologist may be best suited to remove the specimen en bloc, consisting of the fibrous capsule with implant in place and non-disturbed effusion fluid. Upon opening the capsule, there is a yellowish, turbid fluid, sometimes with fibrinoid strands and in some cases membranous material is floating in the cavity. The implant is opaque and is covered by a thin layer of white or yellow material that may be misinterpreted as pus or fibrin (Fig. 4c). Routine microbiologic cultures are almost always negative, and if positive, most likely represent contamination from handling [31, 47]. Full display of the capsule shows that the luminal surface is pink, occasionally with fibrinoid strands or detached fragments of pseudomembranous tissue (Fig. 4b), but a distinct mass is not detected. However, upon microscopic examination, most of the surface is covered by a layer, a few cells [3-5] in thickness of anaplastic large cells or necrotic cells that appear as a fibrinoid or granular material at first glance, but on closer inspection contains ghosts of large cells, albeit shrunken. Any area of induration should be sampled. Secondary changes such as granulation tissue, fibrosis, or dense chronic inflammatory infiltrate can be found. Occasional capsules, particularly those being in place for more than 10 years, may show focal areas of calcification. (unpublished data)

There are two clinical scenarios where the diagnosis of breast implant ALCL is particularly challenging: (1) the patient who recently (days to few weeks) underwent drainage or aspiration of the effusion; and (2) the patient who recently underwent removal of an implant without capsulectomy, and later undergoes removal of the capsule. (unpublished data). In the first scenario, aspiration or drainage of the effusion may lead to re-accumulation of the fluid in a few weeks or months, but the number of lymphoma cells may be markedly decreased by dilution, and there may be a predominance of neutrophils or histiocytes [51]. In the second scenario a procedure such as capsular biopsy, drainage by FNA or removal or replacement of the implant, may yield a false negative for tumor even when using CD30 immunohistochemistry. (unpublished data) We 

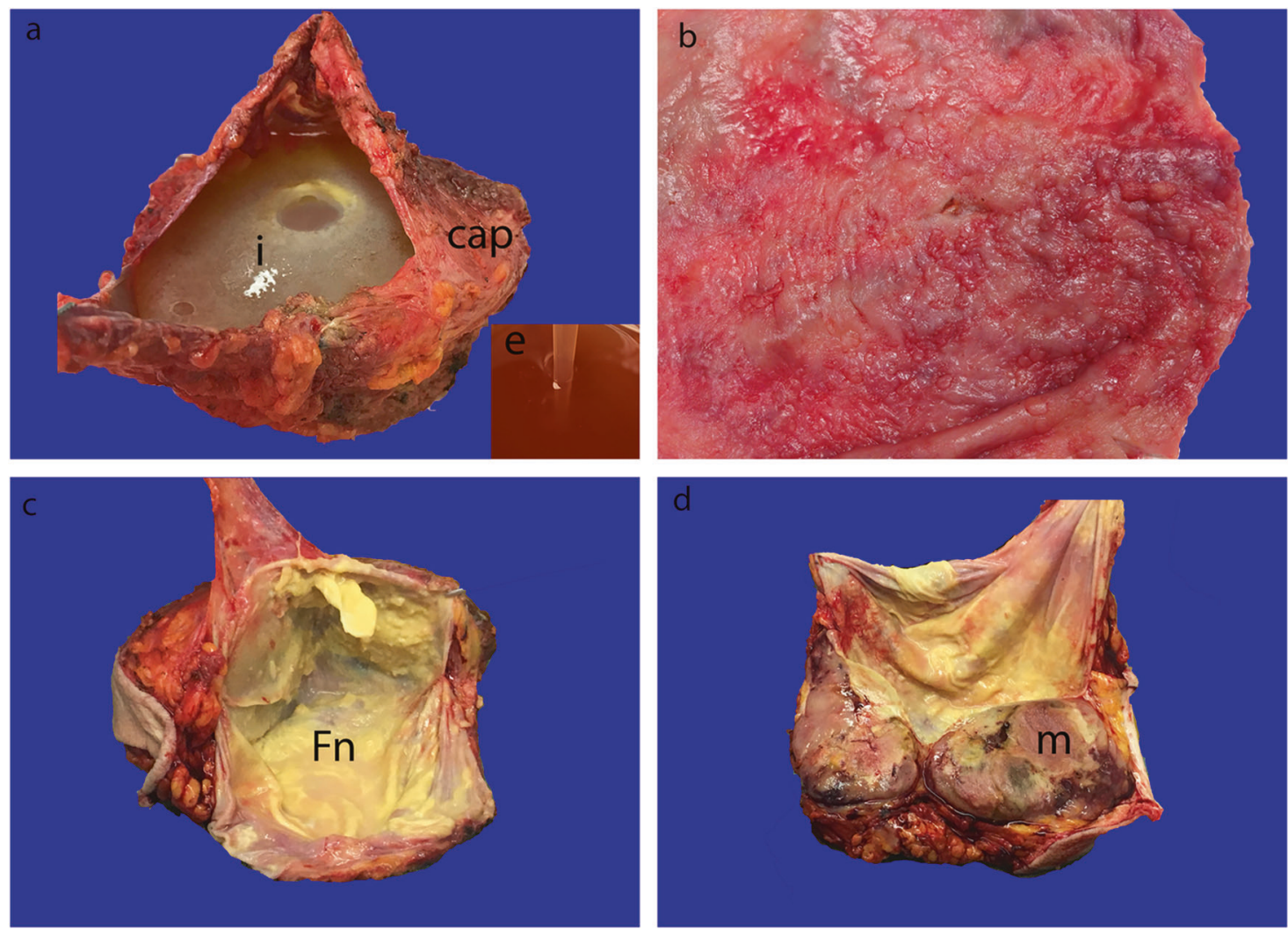

Fig. 4 Gross appearance of resected breast implant ALCL. a Fibrous capsule (labeled cap) opened to show silicone implant (labeled i) and surrounding effusion fluid; inset, aspirated effusion fluid with a turbid appearance. b Luminal surface of resected fibrous capsule showing an

irregular surface involved by lymphoma. c Breast implant capsule opened to show abundant yellowish and thick fluid (fn). d Breast implant capsule opened to show a large tumor mass (bisected, labeled $\mathrm{m}$ )

have identified residual lymphoma upon further and careful sampling on any irregularity, or granularity in the capsule (unpublished data).

If a tumor mass is detected preoperatively, we recommend en bloc resection with clear margins. The specimen should be intact when submitted to the pathologist. Orientation of the specimen should match the preoperative imaging studies or it should be clearly indicated by the surgeon to map the areas of more concern (unpublished data). Areas of tumor are generally felt or readily visualized (Fig. 4c) $[28,47]$. In some patients, tumor infiltrating the capsule and beyond may be firmly attached to the implant surface, causing distortion of the implant. The tumor may present as a localized mass, sometimes as a plaque-like, of variable size within or beyond the outer portion of the capsule (Fig. 4d). We recommend extensive sampling of any areas of suspected tumor (see below).

\section{Tumor handling and sampling of specimens}

Adequate and thorough sampling is required for optimal handling of pathologic specimens involved by breast implant ALCL (unpublished data). In our experience,

histologic sections of the capsule oriented on edge are best for appropriate histologic examination, and this can be achieved by fixing the capsule overnight on a flat surface. At this time, there is no standard method for sampling in patients suspected of having breast implant ALCL. The last time the College of American Pathologists (CAP) issued recommendations for sampling of capsules of patients with implants was in 1995 [52], a time when breast implant ALCL was not recognized as a disease entity. A survey of 413 institutions in 1999, mostly in the United States, showed that $10.7 \%$ of institutions had policies that exempted submitting "mammary implants" for pathology examination, and $63 \%$ had policies that recommended "mammary implants" for gross examination only [53]. In our opinion, these policies need to be modified. A standardized method of handling breast implants may increase the detection of this entity. Although firm data are missing at this time, we propose mapping the capsule when gross lesions are not identified, and we suggest at least two random histologic sections from each superior, anterior, inferior, posterior, medial, and lateral aspects of the capsule (unpublished data). Gross identification of a mass should be followed by thorough evaluation. Assessment of margins, 
Fig. 5 Histologic tumor staging of breast implant ALCL: a T1, lymphoma cells are confined to the luminal space (labeled *); H\&E, 100x; inset, higher magnification of lymphoma cell morphology: H\&E, 400×. b T1, CD30 immunohistochemistry, $100 \times$; inset, CD30, $400 \times$. c T2, mild infiltration of lymphoma cells into the capsule (labeled **); H\&E, 100×. d T2, CD30, 100x. (e) T3, sheets of lymphoma cells into but not beyond the capsule (labeled $* *$ ); H\&E, 40x. f T3, CD30, 40x. g T4, lymphoma cells extending beyond the capsule; H\&E, 10x. h T4, CD30, 10x
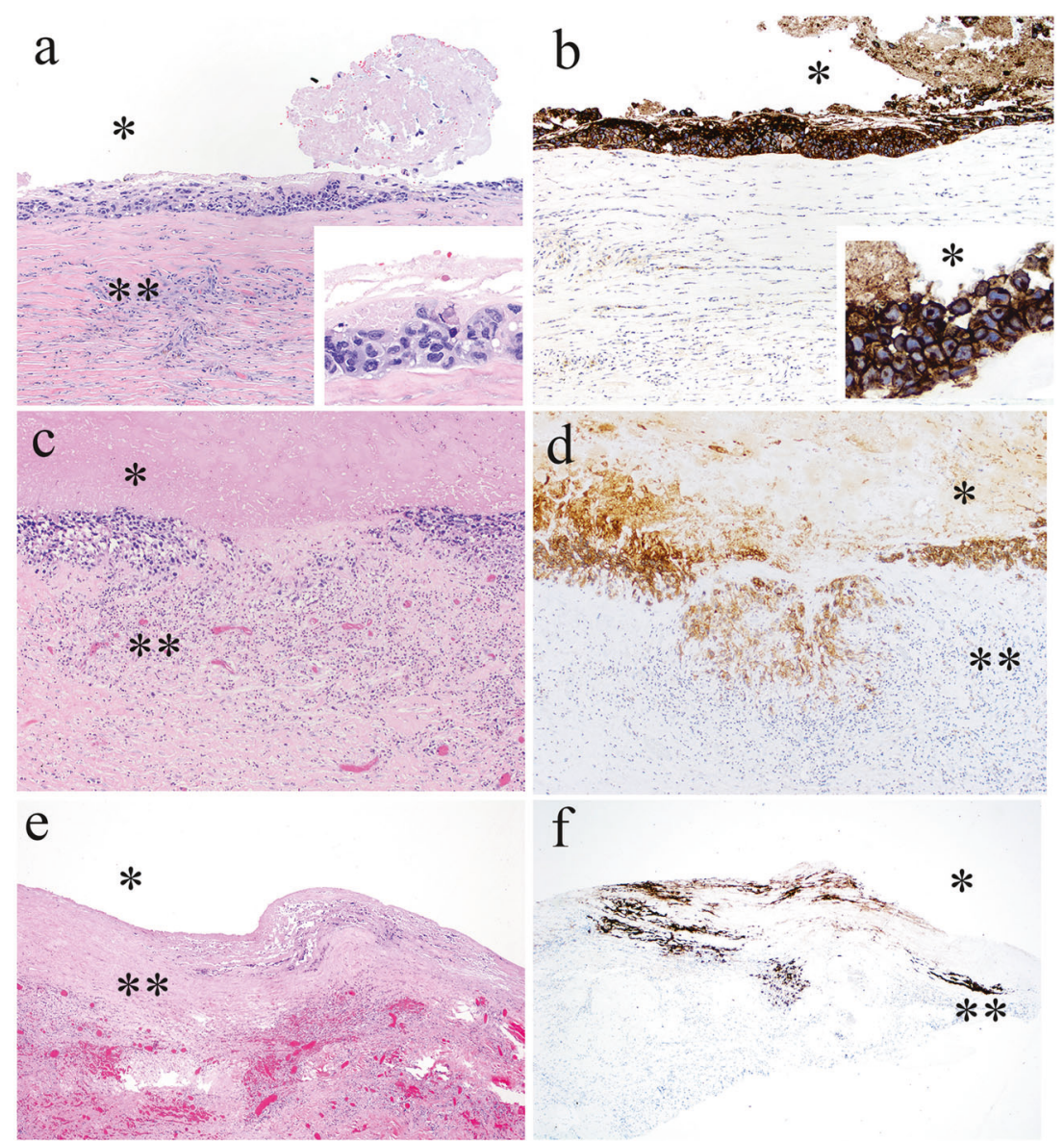

f
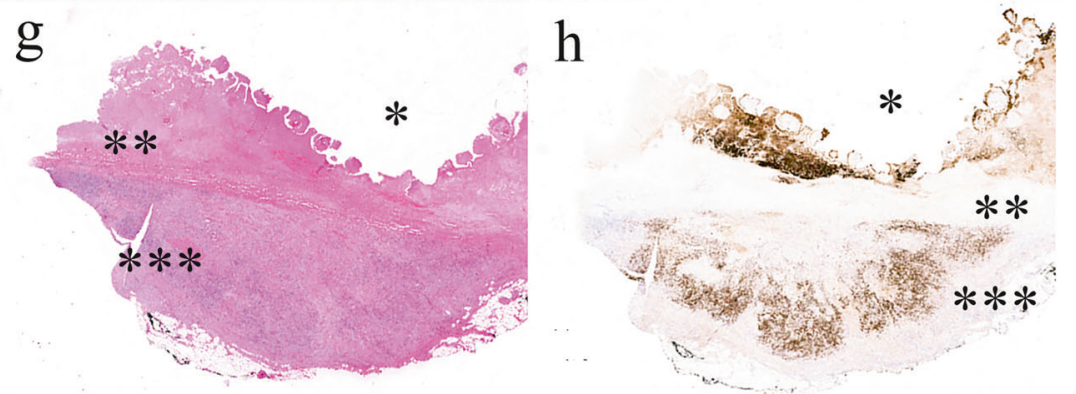

preferably inked, is also recommended, since complete excision of capsule and tumor with negative margins have been shown to lead to optimal outcomes [34]. At this time, there is no recommendation for a specific margin width, and margins may be close without evidence of higher recurrence rates. Obviously, these suggestions can be modified once additional data to determine best practices become available.

\section{Histopathologic features}

In patients who present with effusion and no grossly identifiable capsule lesions, the most characteristic finding is a layer of tumor cells with extensive necrosis along the luminal side of the capsule. We estimate that usually more than $90 \%$ of the tumor cells are necrotic (unpublished data). Some areas of capsule lining are devoid of cells or necrotic material. In some cases, no viable cells are found attached to the capsule; however, cytological preparations of the effusion are likely to reveal viable tumor cells. Lastly, scrapings of the implant surface submitted as cytological smears or cell block may also help to detect lymphoma cells [47].

The lymphoma cells of breast implant ALCL resemble systemic ALCL at nodal or extranodal sites $[2,27,28,31$, 48, 54-65]. The lymphoma cells are large, non-cohesive with pleomorphic and anaplastic morphology, and abundant 
Fig. 6 Cytological features of breast implant ALCL.

a Effusion fluid negative for lymphoma. Small lymphocytes and monocytes are present; Wright-Giemsa stain, 1000x. b Multiple large anaplastic lymphoma cells with irregular nuclei, prominent nucleoli and abundant, occasionally vacuolated cytoplasm; Diff Quik, 1000x. c Multiple large lymphoma cells with irregular nuclei, prominent nucleoli and abundant cytoplasm admixed with small lymphocytes; Papanicolaou stain, 1000x. d Cell block preparation of effusion fluid showing a cluster of lymphoma cells; H\&E, 400x

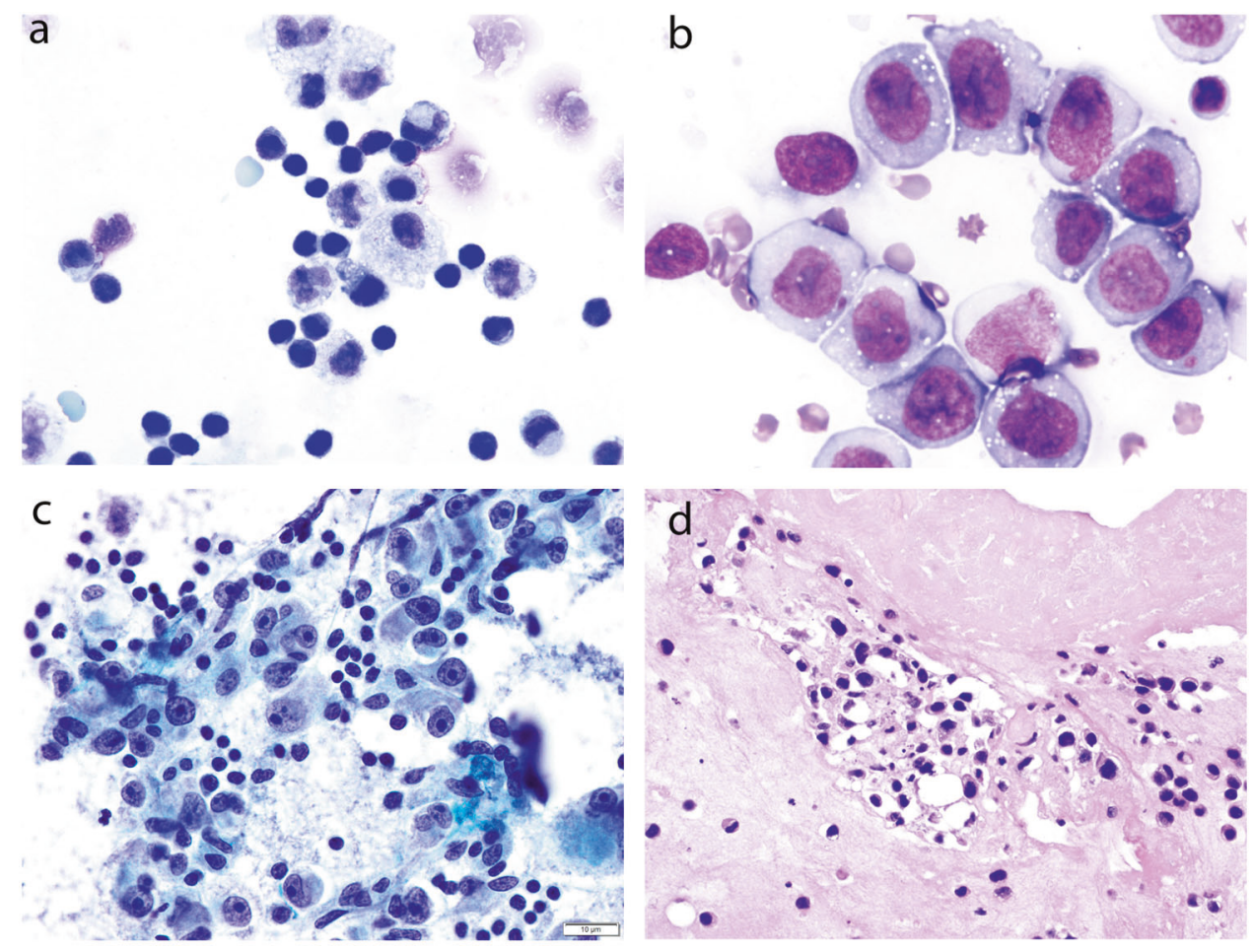

eosinophilic cytoplasm. The cell nuclei are large, oval or multilobated, with vesicular or dense chromatin, and usually have prominent nucleoli and frequent mitoses (Fig. 5a inset). The so-called hallmark cells with a horseshoe-, kidney-, or wreath-shaped nucleus are found in approximately $70 \%$ of cases, but their frequency among neoplastic cells is variable, and more common is that they are rather few. (unpublished data) The lymphoma cells appear as small clusters within the effusion or floating clots as the inner lining of the fibrous capsule. Abundant necrotic "ghost" cells rather than fibrin are noted on close inspection in most cases. Immunohistochemistry using CD30 highlights almost all the identified lymphoma cells on hematoxylin and eosin, as well as the outlines of ghost cells or the necrotic debris that is distinctly granular with anti-CD30 (Fig. 5b).

We have proposed a tumor staging system to assess the degree of tumor infiltration into the capsule [34, 47, 66]. T1 signifies that the lymphoma cells are confined to the luminal surface (Fig. 5a, b). T2 occurs when there is minimal infiltration into the capsule (Fig. 5c, d). T3 indicates sheets of tumor cells invasive deep into the capsule but not beyond (Fig. 5e, f), and T4 designates the presence of tumor cells beyond the capsule; T4 usually correlates with the clinical detection of a mass (Fig. $5 \mathrm{~g}, \mathrm{~h}$ ). The neoplastic cells in stages $\mathrm{T} 3$ and $\mathrm{T} 4$ are commonly admixed with inflammatory cells (unpublished data). This $\mathrm{T}$ stage is included in a clinical Tumor Node Metastasis (TNM) solid tumor staging system modeled after the American Joint Committee on Cancer TNM solid tumor staging, and now advocated by the National Comprehensive Cancer Network[66]. Using this system, the spectrum of breast implant ALCL consisted of the following stages: IA $(35.6 \%)$, IB $(11.5 \%)$, IC (13.8 \%), IIA (25.3\%), IIB $(4.6 \%)$, III $(9.2 \%)$, and IV (0 to $9 \%)$ [34].

\section{Diagnosis by cytologic examination}

The most common clinical presentation of breast implant ALCL is effusion around the breast implant that occurs a median of 9 years after implantation, thus falling in the category of "late seroma" defined as an effusion $\geq 1$ year after initial surgery. Fluid collections shortly after the placement of breast implants are common and often represent a hematoma or an effusion related to the surgical procedure itself, or infection. Therefore, a "late seroma" requires further investigation [67-69]. Fine needle aspiration with cytological evaluation provides a fast, safe, and effective method for evaluation of the effusion in cases of breast implant ALCL. An effusion negative for lymphoma is shown in Fig. 6a.

Breast implant ALCL in Wright-Giemsa or May-Grünwald-Giemsa stained slides shows highly cellular specimens composed of a homogeneous population of non-cohesive large cells with irregularly lobated nuclei, prominent nucleoli and abundant cytoplasm [2, 30, 55, 60, $65,70,71]$. Cells are typically four to five times larger than a small mature lymphocyte. The cytoplasm is clear or light blue, usually containing scattered small vacuoles, and the 
Table 2 Summary of the immunophenotype and molecular features of breast implant ALCL cases

\begin{tabular}{|c|c|c|}
\hline & $(+)$ cases $(n)$ & $\%$ \\
\hline $\mathrm{CD} 2(n=76)$ & 40 & 52.6 \\
\hline CD3 $(n=146)$ & 47 & 32.2 \\
\hline CD4 $(n=130)$ & 104 & 80.0 \\
\hline $\operatorname{CD} 5(n=101)$ & 26 & 25.7 \\
\hline CD7 $(n=69)$ & 5 & 7.2 \\
\hline $\operatorname{CD} 8(n=108)$ & 13 & 12.0 \\
\hline $\mathrm{CD} 15(n=68)$ & 28 & 41.2 \\
\hline $\mathrm{CD} 20(n=115)$ & 0 & 0 \\
\hline $\operatorname{CD} 30(n=167)$ & 167 & 100 \\
\hline CD43 $(n=99)$ & 80 & 80.8 \\
\hline $\operatorname{CD} 45(n=110)$ & 74 & 67.3 \\
\hline $\operatorname{ALK}(n=155)$ & 0 & 0 \\
\hline EBER $(n=66)$ & 0 & $0 \%$ \\
\hline EMA $(n=94)$ & 58 & 61.7 \\
\hline Granzyme B $(\mathrm{n}=83)$ & 56 & 67.5 \\
\hline $\operatorname{PAX} 5(n=45)$ & 0 & 0 \\
\hline Perforin $(n=17)$ & 10 & 58.8 \\
\hline TIA-1 $(n=75)$ & 52 & 69.3 \\
\hline TCR $\beta$ F1 $(n=63)$ & 7 & 11.1 \\
\hline TCR $\gamma(n=59)$ & 6 & 10.2 \\
\hline$T R B(n=12)$ & 5 & 41.7 \\
\hline$T R G(n=34)$ & 26 & 76.5 \\
\hline
\end{tabular}

$A L K$ anaplastic lymphoma kinase, EBER Epstein-Barr virus encoded RNA, EMA Epithelial membrane antigen, TCR $\beta F 1$ T-cell receptor $\beta$ chain, TCR $\gamma$ T-cell receptor $\gamma$ chain, TRB T-cell receptor $\beta$ monoclonal rearrangement, TRB T-cell receptor $\gamma$ monoclonal rearrangement

cellular outlines demonstrate cytoplasmic fragmentation (Fig. 6b). Less frequently, the cytoplasmic vacuoles are abundant and confluent giving the neoplastic cells a signet ring appearance. The background is granular or fibrinoid, sometimes with karyorrhectic debris. Lymphoglandular bodies are not typically seen. Inflammatory cells in the background are variable, and can range from few to abundant small lymphocytes, neutrophils, histiocytes or eosinophils. The Papanicolaou stain demonstrates similar features to Wright-Giemsa, although the nuclei appear more hyperchromatic and nuclear lobation can be more apparent; prominent nucleoli are common, and the cytoplasm appears opaque, basophilic, or cyanophilic [55, 63, 65, 72] (Fig. 6c).

Preparation of a cell block is of great benefit for both morphologic and immunohistochemical evaluation (Fig. 6d) $[54,55,60,63,64,70,73]$. We have evaluated cytologic specimens from 18 patients that confirm the spectrum reported in the literature. Combining our 18 patients with 29 cases from the literature, the sensitivity of the initial cytological evaluation is $78 \%$, that increased to $83 \%$ with reevaluation of effusions initially reported as negative (unpublished data). When breast implant ALCL is successfully identified by cytologic evaluation, immediate removal of the implant results in excellent patient outcomes. The overall survival in this patient cohort is more than $95 \%$. (unpublished data).

\section{Immunophenotype}

Although some cases of breast implant ALCL reported in the literature were assessed by flow cytometry, in most cases the immunophenotype has been determined by immunohistochemistry. A selected list of markers expressed by breast implant ALCL is shown in Table 2 . CD30 is expressed in all cases and by most of the lymphoma cells (Fig. 5b, d, f, h). Other markers frequently expressed in breast implant ALCL are CD43 ( 80\%), CD4 ( 80\%), TIA-1 ( 69\%), granzyme B ( 68\%), epithelial membrane antigen ( 60\%), CD3 $(\sim 33 \%)$, and CD8 $(\sim 10 \%)$. Most cases of breast implant ALCL do not express a T-cell receptor (TCR), but TCR $\alpha \beta(\beta \mathrm{F} 1)$ and TCR $\gamma \delta$ have been reported in $11.1 \%$ and $10.2 \%$ of cases, respectively. In our experience with over 100 cases of breast implant ALCL, all cases have been negative for anaplastic lymphoma kinase (ALK). Taylor et al. reported ALK-1 expression in 8\% of their cases [74]. We suspect that these ALK-positive neoplasms may represent systemic disease presenting initially in the breast near an implant as we have observed similar cases. Cases of breast implant ALCL are negative for CD1a, TdT, and cyclin D1. Epstein-Barr virus small encoded RNA (EBER) was negative in $100 \%$ of 66 cases tested.

\section{Cytogenetic features}

Conventional cytogenetic studies of breast implant ALCL cases have been performed on relatively few cases (Table 3 ) $[48,70,75]$. Lechner et al. performed conventional cytogenetic and spectral karyotyping analysis of three breast implant ALCL cell lines derived from patient samples; these cell lines showed hypertriploid, and complex karyotypes [30]. Patients with an aggressive clinical course also have been shown to have a complex karyotype [48, 70, 76]. George et al. reported a case of breast implant ALCL that relapsed and followed an aggressive course; this case had a complex karyotype at the time of relapse [70].

\section{Molecular genetic findings}

The majority of tested cases of breast implant ALCL carry monoclonal TRG or TRB rearrangements. Based on our review of the literature, $5 / 12(41.7 \%)$ had monoclonal TRB and 26/34 (76.5\%) had monoclonal TRG.(Table 2) We suspect that the rate of monoclonal cases is higher, 
Table 3 Karyotypic findings in patients with breast implant ALCL

\begin{tabular}{|c|c|}
\hline Reference & Karyotype \\
\hline $\begin{array}{l}\text { George EV et al. } \\
{[70]}\end{array}$ & $\begin{array}{l}\text { 45, XX [cp19]dup(X)(q11q28), +1, del(1)(q32), i(1)(q10), add(3)(p11), der(3), t(2;3) } \\
(\mathrm{p} 12 ; \mathrm{p} 26),+6, \operatorname{der}(6) \mathrm{t}(6 ; 8)(\mathrm{q} 12 ; \mathrm{q} 21.3) \times 2, \operatorname{add}(8)(\mathrm{q} 11.2), \operatorname{add}(11)(\mathrm{q} 23), \operatorname{add}(14) \\
(\mathrm{p} 11.1),-15,-17,-20,80 \sim 91, \text { idem }[\mathrm{cp} 2]\end{array}$ \\
\hline Alobeid B et al. [48] & $\begin{array}{l}116-123,55 \mathrm{~N} 4, \mathrm{XX}, 71, \operatorname{add}(1)(\mathrm{p} 36.3), \mathrm{i}(1)(\mathrm{q} 10), \mathrm{hsr}(1)(\mathrm{q} 21 \mathrm{q} 25), \mathrm{p} 2, \mathrm{p} 362, \mathrm{p} 6, \mathrm{hsr}(7) \\
(\mathrm{q} 32 \mathrm{q} 35) 62, \mathrm{i}(8)(\mathrm{q} 10), \mathrm{p} 9, \mathrm{p} 10, \operatorname{inv}(11)(\mathrm{p} 15.1 \mathrm{q} 22.1) 63, \operatorname{add}(12)(\mathrm{q} 24.1), 713,714,715, \mathrm{i} \\
(17)(\mathrm{q} 10), \mathrm{p} 19,720, \mathrm{p} 1 * 8 \operatorname{mar}[\mathrm{cp} 13] / 46, \mathrm{XX}, \operatorname{inv}(11)(\mathrm{p} 15.1 \mathrm{q} 22.1)[7] .\end{array}$ \\
\hline $\begin{array}{l}\text { Lechner MG et al. } \\
\text { [75] }\end{array}$ & $\begin{array}{l}48, \mathrm{XX},=\operatorname{add}(2)(\mathrm{q} 21), \operatorname{dup}(2)(\mathrm{q} 31 \mathrm{q} 35), \operatorname{add}(5)(\mathrm{p} 13), \operatorname{del}(10)(\mathrm{p} 11.2 \mathrm{p} 13),+\operatorname{der}(? 12) \mathrm{t} \\
(12 ; 17)(\mathrm{q} 13 ; \mathrm{q} 21),-16,-20,+\operatorname{mar} 1-2[5]\end{array}$ \\
\hline $\begin{array}{l}\text { Lechner MG et al. } \\
\text { [75] }\end{array}$ & $\begin{array}{l}76<3 \mathrm{~N}>, \mathrm{XXX},+1,+2, \operatorname{der}(4) \mathrm{t}(1 ; 4) 9 \mathrm{q} 42 ; \mathrm{q} 25), \operatorname{der}(4) \mathrm{t}(4 ; 4) 9 \mathrm{p} 16 ; \mathrm{q} 31.3),+5,+ \\
\operatorname{der}(6) \mathrm{t}(6 ; 13)(\mathrm{q} 13 ; \mathrm{q} 22), \operatorname{der}(7) \mathrm{t}(7 ; 19)(\mathrm{p} 13 ; \mathrm{q} 13.4) \mathrm{t}(16 ; 19)(\mathrm{q} 22 ; ? \mathrm{q} 13.1) ? \operatorname{trp}(19) \\
(\mathrm{q} 13.1 \mathrm{q} 13.4), \operatorname{del}(8)(\mathrm{p} 21 \mathrm{p} 23),+\operatorname{del}(10)(\mathrm{p} 11.2 \mathrm{p} 13) \mathrm{x} 1 \text { or } \mathrm{x} 2, \operatorname{der}(15) \mathrm{t}(9 ; 15)(\mathrm{p} 13 ; \\
\mathrm{p} 11.2) \times 2,+17,18, \mathrm{t}(18 ; 20)(\mathrm{q} 11.2 ; \mathrm{q} 13.1), \operatorname{der}(19) \mathrm{t}(18 ; 19)(\mathrm{q} 21.3 ; \mathrm{q} 13.1)[23]\end{array}$ \\
\hline $\begin{array}{l}\text { Lechner MG et al. } \\
\text { [75] }\end{array}$ & $\begin{array}{l}\text { 81,3n.,XXX, }+\operatorname{der}(\mathrm{X}) \mathrm{t}(\mathrm{X} ; 11)(\mathrm{q} 28 ; \mathrm{p} 14), \operatorname{del}(1)(\mathrm{q} 21), \operatorname{der}(1) \operatorname{del}(1)(\mathrm{p} 13 \mathrm{p} 34) \operatorname{inv}(1) \\
(\mathrm{p} 13 \mathrm{q} 42) \mathrm{t}(1 ; 6)(\mathrm{q} 42 ; \mathrm{p} 23),+2,+5, \operatorname{der}(6) \mathrm{t}(1 ; 6)(\mathrm{q} 42 ; \mathrm{p} 23), \operatorname{der}(7) \mathrm{t}(7 ; 1)(\mathrm{q} 32 ; \mathrm{p} 32) \mathrm{t}(1 ; 2) \\
(\mathrm{p} 36.3 ; \mathrm{p} 23),+\operatorname{der}(7) \mathrm{t}(7 ; 1)(\mathrm{q} 32 ; \mathrm{p} 23),+\operatorname{der}(7) \mathrm{t}(7 ; 1)(\mathrm{q} 32 ; \mathrm{p} 23) \operatorname{dup}(1)(\mathrm{p} 32 \mathrm{p} 36.3) \mathrm{t} \\
(1 ; 2)(\mathrm{p} 36.3 ; \mathrm{p} 23), \operatorname{del}(8)(\mathrm{q} 21 \mathrm{q} 22), \operatorname{der}(8) \operatorname{inv}(8)(\mathrm{p} 21 \mathrm{q} 11.2) \operatorname{dup}(8)(\mathrm{q} 11.2 \mathrm{q} 13) \times 2,+\operatorname{der} \\
(8) \mathrm{t}(6 ;(\text { karyotype cuts off), also }+10,+11,+\operatorname{der} 12,-16,+19,-20,+\operatorname{der} 20,+ \\
21 \times 2 \text { (based on images of G-banded metaphases) }\end{array}$ \\
\hline Hart AM et al. [76] & Complex; no details \\
\hline
\end{tabular}

however the success rate to assess clonality is not high because of the usual scarcity of tumor cells and the abundance of necrosis [31].

A number of chromosomal translocations have been identified in other well-known types of ALCL including systemic ALK+ and ALK-negative ALCL. ALK+ALCL is characterized by $A L K$ translocations whereas subsets of ALK-negative ALCL cases carry translocations involving DUSP22 or TP63 with a good or poor prognosis, respectively [77, 78]. In contrast, none of the above mentioned translocations have been identified in breast implant ALCL, highlighting the distinctive biologic features for breast implant ALCL [38, 45]. Oishi N et al. [38]. also reported activating mutations in JAK1 and STAT3.

\section{Pathogenesis}

The pathogenesis of breast implant ALCL is not well defined, however, several plausible mechanisms have been proposed. As breast implant ALCL has arisen in patients with either silicone or saline filled implants, it seems more likely that the silicone shell surface rather than the implant contents is involved in pathogenesis.

The role of chronic inflammation associated with implants has been consistently noted as a factor triggering the lymphocyte transformation and lymphomagenesis [2, 79, 80]. Chronic antigenic stimulation may lead to recruitment, proliferation and expansion of $\mathrm{T}$ cells, prolonging T-cell lifespan, and leading to clonal expansion and eventually to malignant transformation. Silicone has been known to be immunogenic since originally used as a liquid for breast expansion in the 1940s [81-84]. Silicone implants and silicone elastomeric capsules lining saline implants are plausible sources of a chronic immunemediated inflammatory response. Presumably, the shell of the implant degrades over time resulting in leakage of antigens that elicit a host immune response [85]. The shedding of silicone particles is more pronounced with textured implants [30]. In a study by Meza-Britez et al., inflammation predominantly with a T-cell phenotype around breast implants was statistically more common in patients with textured breast implants as compared to smooth implants [86].

In vitro studies of breast implant ALCL cells by $\mathrm{Xu}$ et al. [87] and Wolfram et al. [88] revealed a genetic and cytokine profile consistent with interleukin 17-producing T-cells (Th17 T-cells) rather than Th1 or Th2 patterns. Th17 cells are thought to be important drivers of the inflammatory process in tissue-specific autoimmunity [87, 89]. Th17 cells also have been implicated in stimulating the immune response to silicone implants [88]. Kadin et al. reported that breast implant ALCL cell lines and anaplastic cells in clinical specimens produce IL-13, the signature cytokine of allergic inflammation, further supporting the role of inflammation in the pathogenesis of breast implant ALCL [90]. Kadin et al. used gene expression array analysis, flow cytometry and immunohistochemistry to study breast implant ALCL cell lines. They reported high expression of the transcription factor JunB and the cytokines interferon gamma and IL-17F, suggestive of a Th17/Th1 phenotype [91].

Activation of the JAK/STAT3 signaling pathway and expression of cytotoxic molecules in breast implant ALCL cell lines is comparable to findings observed in systemic ALK +ALCL, specifically upregulation of Th17 related genes [30]. 

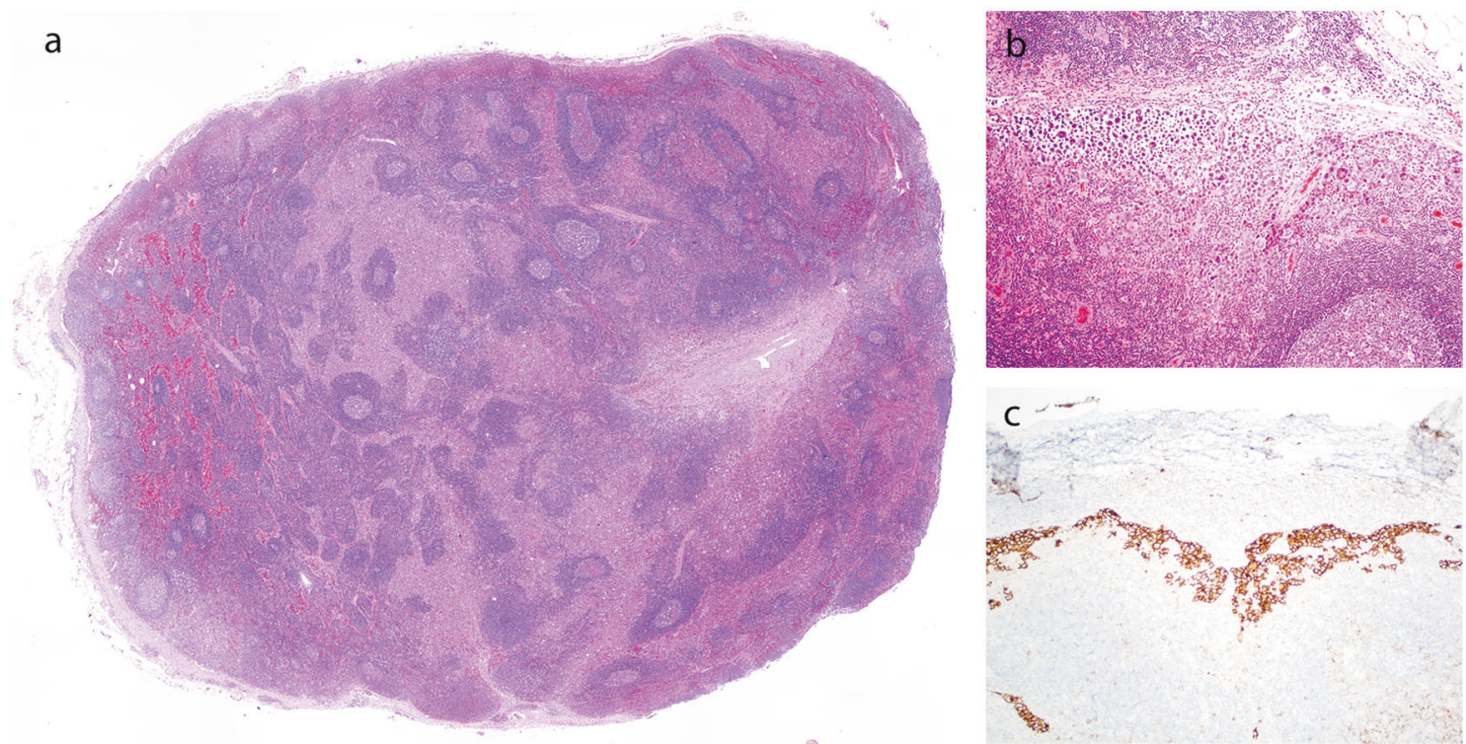

Fig. 7 Lymph node involvement by breast implant ALCL. a Enlarged lymph node with partial architectural distortion due to involvement by breast implant ALCL in sinuses and interfollicular areas; H\&E, 40x. b
Higher magnification shows extensive sinusoidal involvement; H\&E, 100x. c CD30 immunohistochemistry highlights the lymphoma cells within sinuses, $100 x$
$\mathrm{Hu}$ et al. based on microbiome studies of textured implants in patients with breast implant ALCL have proposed that the trigger for chronic inflammation lies in the presence of high bacterial loads and biofilms, particularly from Gram negative bacteria such as Ralstonia species [33]. It is thought that these bacteria could produce lipopolysaccharide antigens that may stimulate cytokine production resulting in chronic Th1 cell stimulation [33, 91]. These findings require further confirmation [92].

\section{Cell lines}

Lechner et al. developed a robust working model for breast implant ALCL tumor cell biology [30]. They generated three cell lines from primary tumor specimens of patients with breast implant ALCL, which they designated TLBR1-3 $[30,75]$. All cell lines showed T-cell receptor $\gamma$ monoclonality by multiplex polymerase chain reaction. Using Western blot analysis, these authors showed activation of STAT3. Furthermore, the STAT3 negative regulator SHP-1 was significantly downregulated in TLBR cells. STAT3 specific inhibition produced cell death in all three cell lines in a dose-dependent manner [30, 75]. These findings suggest that activation of the JAK/ STAT3 signaling pathway plays a role in the pathogenesis and survival of breast implant ALCL. Oishi et al. [38]. demonstrated phosphorylated STAT3 expression in 25 clinical specimens of breast implant ALCL, providing further support of activation of this pathway. These cell lines also strongly express Notch1 and Notch2, and Notch1 activation was high in an aggressive and fatal case of breast implant ALCL [30].

These cell lines also secret various cytokines, with IL-6 and IL-10 being most prominent. The three cell lines were strongly positive for IL-2R $\alpha$ IL-2R $\beta$, secreted detectable amounts of IL-2 in culture, exhibited IL-2 dependent growth in vitro and died in the absence of IL-2 [30].

\section{Tumor progression}

About $35 \%$ of patients with breast implant ALCL have clinical or radiologically enlarged regional lymph nodes $[31,32]$. It is established that silicone can elicit regional lymphadenopathy in patients with breast implants and without ALCL, known as siliconoma (Fig. 7a-c). The frequency of siliconomas in patients with breast implant ALCL is unknown at this time. The frequency of lymphadenopathy as a result of dissemination of breast implant ALCL proven by biopsy or highly suspicious cases by imaging studies is $23 \%$ at diagnosis or follow-up [46]. The incidence is $17 \%$ when the definition of lymph node involvement is limited only to patients with pathologic assessment of lymph nodes [46]. Breast implant ALCL involves lymph nodes most often in a sinusoidal pattern, in over $90 \%$ of cases, but perifollicular, interfollicular, and diffuse patterns of involvement also occur and, in some cases, the neoplasm can mimic Hodgkin lymphoma [46].

When breast implant ALCL infiltrates beyond the capsule into surrounding fibrous tissue or breast parenchyma, it 

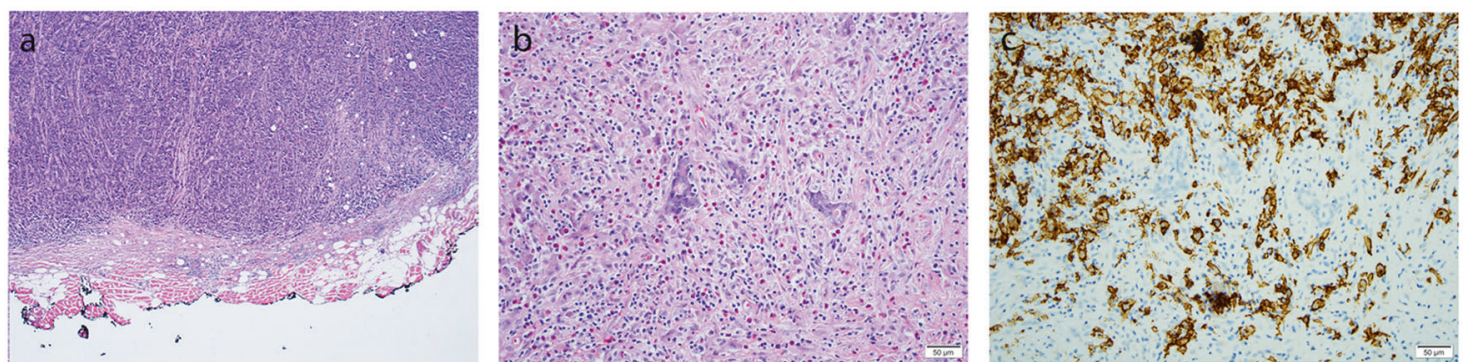

200x. c CD30 highlight numerous lymphoma cells surrounding breast ducts, 200x. The prognostic significance of these patterns of invasion is currently unknown lymphoma cells pushing toward resection margin (inked black); H\&E, $40 \times$. b Lymphoma cells surrounding and distorting breast ducts; H\&E,

Table 4 Events after various therapy modalities and management of breast implant ALCL

\begin{tabular}{llll}
\hline Intervention & $\mathrm{n}$ & Event & $\%$ \\
\hline FNA & 36 & 25 & $69 \%$ \\
Limited Surgery & 46 & 39 & $85 \%$ \\
Chemotherapy & 39 & 10 & $26 \%$ \\
Radiation & 51 & 15 & $29 \%$ \\
Complete Surgery & 74 & 4 & $5 \%$ \\
\hline
\end{tabular}

Events were defined as recurrence of effusion, mass or death, whichever occurred first, after an initial intervention considered optimal management (fine needle aspiration, surgical drainage, implant replacement, sampling of the capsule or partial capsulectomy).

can display a "pushing" infiltration pattern (Fig. 8a) or it can surround and distort the breast ducts (Fig. 8b, c). The prognostic significance of these features is currently not yet determined.

\section{Therapy}

Although most patients with breast implant ALCL have excellent prognosis, patients commonly undergo noncurative procedures before a definitive therapy is performed. Clemens et al demonstrated that the best outcomes are achieved by complete capsulectomy with removal of implants and all evidence of disease [34]. Table 4 illustrates the rate of events after patients undergo non-curative procedures. Fine needle aspiration, implant replacement or excision or partial/incomplete resection of the capsule lead to a high rate of recurrence and some cases progression of disease [34]. Patients who eventually underwent complete capsulectomy and implant removal achieved complete remission in $93 \%$ of cases with effusions in the absence of a mass. This decreased to a $72 \%$ rate of complete remission if a mass was also present but no complete capsulectomy was performed. The complete remission was lasting and observed beyond 5 years. Despite a more guarded prognosis, documented recurrent or persistent disease, the overall prognosis remains favorable [34]. Diagnosis and treatment follows standardized evidence-based guidelines established by the National Comprehensive Cancer Network (NCCN) [66]. The role of chemotherapy is reserved for non-resectable cases.

Chemotherapy following the typical approach and protocols used for patients with systemic ALCL has been given to about half of the well documented patients with breast implant ALCL reported. Most of these patients were treated with standard regimens containing cyclophosphamide, doxorubicin, vincristine and prednisone (CHOP and $\mathrm{CHOP}$ like). Very few patients received more intensive regiments such as Hyper-CVAD or addition of etoposide to other agents (CHOEP, ICE). A few patients have undergone ablative chemotherapy followed by autologous stem cell transplant. A few other patients underwent second line chemotherapy upon relapse [31]. The overall and progression-free survival of these patients have been similar to patients who did not receive adjuvant chemotherapy suggesting that chemotherapy is not needed in a subset of patients with breast implant ALCL [31]. Furthermore, in 12 patients who opted for watchful waiting and no treatment beyond capsulectomy, all achieved complete remission (median follow-up, 1 year; range, 0.1 to 10 years) [31]. To date, limited experience with brentuximab vedotin (antiCD30 conjugated with monomethyl auristatin E) has shown promise for patients refractory to chemotherapy or for nonresectable disease [93].

\section{Prognosis and clinical outcomes}

Patients with breast implant ALCL have an excellent prognosis overall (Fig. 9a), clearly better than that of patients with systemic ALCL, both ALK+ and ALK - and similar to primary cutaneous ALCL. A meta-analysis of breast implant ALCL showed that the disease is curable when appropriate management and therapy are utilized [34]. Complete capsulectomy can confer a 5-year overall survival rate of $98.8 \%$ as compared to $57.2 \%$ in patients who did not undergo complete capsulectomy $(p<0.0001)$ (Fig. 9b). Miranda et al. reported a median overall survival (OS) of 12 


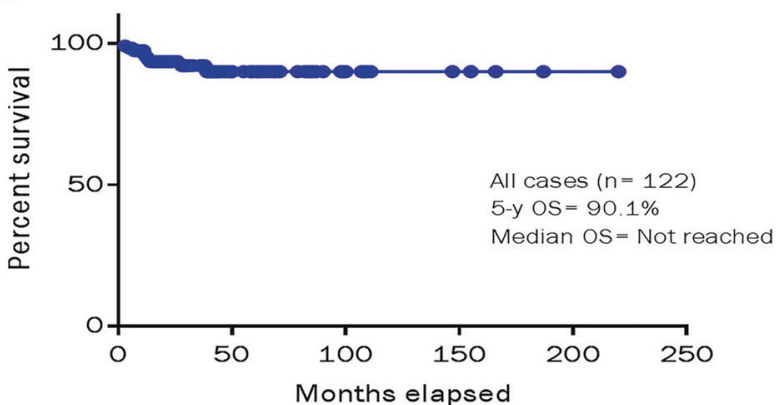

c

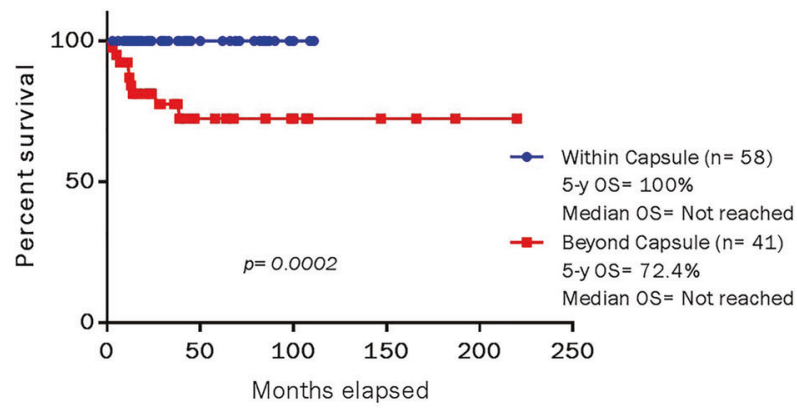

Fig. 9 Survival curves for breast implant ALCL. a Overall survival for 122 patients. b Overall survival of patients treated with complete capsulectomy, with or without additional therapy, compared to those who did not have complete capsulectomy $(p<0.0001)$. c Overall survival of patients with the lymphoma confined within the capsule

years (median follow-up, 2 years; range, $0-14$ years), the 3year overall survival was $97 \%$, and the 5-year OS was $92 \%$ in 60 patients. We and others have noted that patients who present with a tumor mass as opposed to only effusion tend to have a more aggressive disease, including regional lymph node involvement [2,29]. Confinement within the capsule is an excellent prognostic marker with a 5-year OS of $100 \%$ compared to $72.4 \%$ when the tumor extends beyond the capsule ( $p=0.0002)$ (Fig. 9c). Similarly, the lack of lymph node involvement at presentation is also a good prognostic marker (Fig. 9d). A statistically significant difference was found in the OS and progression-free survival in patients with a mass as compared to those without a mass [31, 32]. Similar to these findings, a recent review of outcomes found a 9\% mortality rate in patients with breast implant ALCL [94]. Up to early 2018, sixteen patients worldwide had a fatal outcome $[28,29]$.

\section{Analysis of causality between breast implants and ALCL}

The information gathered over the years points to a causal relationship between breast implants and breast implant ALCL. Clinically, all reported cases presented either with an effusion or a mass around the implants. Imaging studies b

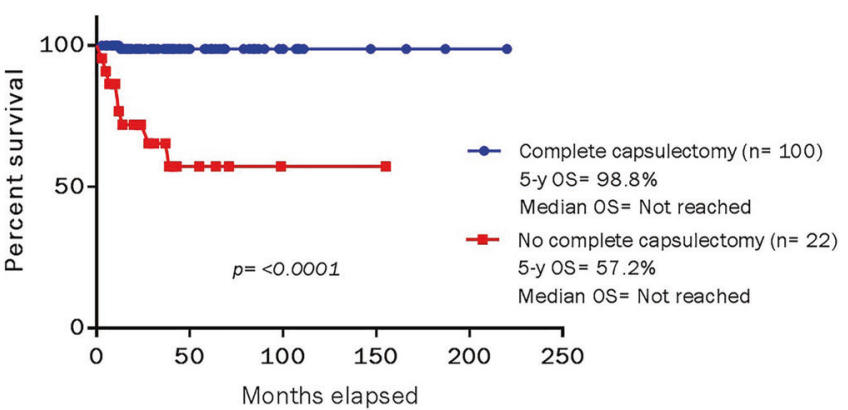

d

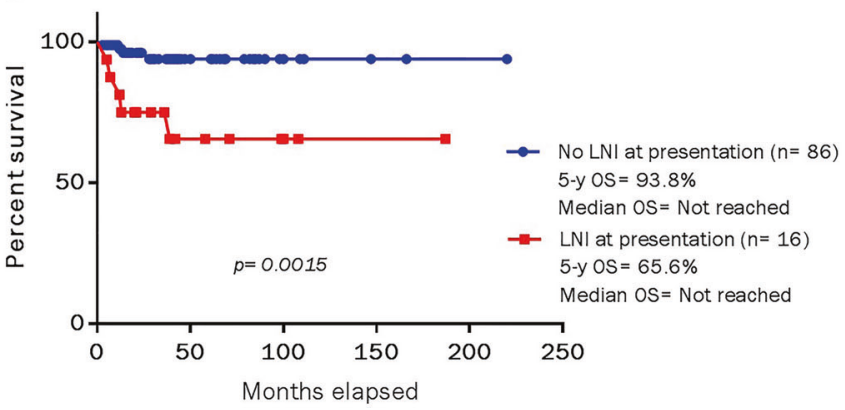

compared to those in whom the lymphoma infiltrated beyond the capsule $(p=0.0002)$. d Overall survival of patients with no lymph node involvement (LNI) at presentation compared to those with LNI at presentation $(p=0.0015)$

show fluid accumulation around implants that appear distorted, commonly suggesting rupture of implant. There is a temporal relationship with most cases of breast implant ALCL occurring at a median of 9 years after implantation [31]. Pathologically, all cases we have reviewed and those reported in the literature have a consistent pattern: all neoplasms grow around the breast implants, and those patients who present with an effusion share the gross fibrinoidnecrotic appearance of the effusion, where usually there is a monomorphic population of large anaplastic cells that uniformly express CD30. All the cases we have included in our studies have disease on the luminal side of the capsule, including those with infiltration beyond the capsule, evidence against the suggestion that the tumor is arising elsewhere and colonizing the outer surface of the capsule. Also compelling is the fact that T-cell lymphomas of the breast represent less than $10 \%$ of all non-Hodgkin lymphoma and less than $2 \%$ are ALCL, compared with $>90 \%$ of ALCL among lymphomas arising around breast implants. Epidemiologically, a cohort study accrued almost 3000 patients with breast implants and followed for 20 years, and two patients developed breast implant ALCL. A case control study in The Netherlands demonstrated an 18-fold increase of ALCL among women with implants. The US Food and Drug Administration-mandated Continued Access 
Table 5 Bradford Hill criteria of causality applied to breast implant ALCL

\begin{tabular}{lll}
\hline$\#$ & Criterion & Argument \\
\hline 1 & Strength & Pathologic evidence \\
2 & Consistency & $>500$ cases reported worldwide \\
3 & Specificity & ALCL is more rare in patients without implants \\
4 & Temporality & Median, 9 years after implantation \\
5 & Biologic gradient & Recurrence or progression if not properly treated \\
6 & Plausibility & Strong association between textured implants, microbiome, and breast implant \\
7 & Coherence & ALCL \\
8 & Experimental evidence & Not yet available \\
9 & Analogy & Other localized lymphomas: Fibrin DLBCL \\
\hline
\end{tabular}

$D L B C L$ diffuse large B-cell lymphoma
Reconstruction/Revision Expansion (CARE) clinical trials were the largest prospective series of textured implants (17,656 women, 31,985 implants) and have six confirmed cases of breast implant ALCL, which yields a prevalence of one in 2943 (95 percent exact Poisson CI, 1351 to 8018 [95, 96]. Of great interest is the acknowledgement that breast implant ALCL patients is a localized disease and that complete surgical resection of capsule and implants leads to curative outcomes.

To summarize the wealth of information exposed in this review, here we applied the Bradford Hill criteria of causality for cases of breast implants ALCL. In 1965, Bradford Hill proposed nine criteria that can be applied in epidemiologic studies to establish a relationship of causality for non-infectious diseases [97, 98]. These criteria were first used to demonstrate the causality between cigarette smoking and lung cancer. The Bradford Hill criteria have been used for a variety of epidemiologic studies and are comparable to the postulates of Koch to prove etiologic evidence in infectious diseases. Table 5 shows the criteria proposed by Bradford Hill that we have applied to the analysis of breast implant ALCL and it is apparent that breast implant ALCL fulfills most of the criteria of causality. (1) Strength of the association is based on the consistent clinical, pathological presentation, and therapeutic response of cases. (2) Consistency is based on the similarity of observations of the findings by multiple investigators throughout the world. (3) Specificity indicates the detection of ALCL in the breast of patients with implants, as opposed to diffuse large B cell lymphoma or marginal zone lymphoma as the most common breast lymphomas in patients without implants [26]. (4) Temporality is supported by the median of 9 years between implantation and manifestation of breast implant ALCL [31]. (5) Biologic gradient for an implant can be interpreted as persistence of disease if implant remains in place or is replaced. (6) Plausibility in identifying the association of ALCL with textured implants as opposed with smooth implants [36]. Furthermore, an association between the microbiome and textured implants has been demonstrated. (7) Coherence. The fact that most women with breast implants do not develop ALCL does not deny that a proportion (albeit minimal) of women develop ALCL. (8) Experimental evidence. There are not animal models where the disease can be reproduced upon exposure to material associated with implants. (9) Analogy. The 2017 WHO classification of lymphoid neoplasms has included the category of fibrin-associated diffuse large B-cell lymphoma, an EBV+large cell lymphoma with usually low tumor burden arising within fibrous walls or pseudocysts in different locations such as renal pseudocyst or lesions in the cardiovascular system such as myxomas or cardiac thrombus [99, 100]. Breast implant ALCL bears some similarities to these tumors in that it presents confined by a fibrous capsule around a breast implant. In both lymphomas, localized chronic inflammation with local immunosuppression appears to play a significant role in the microenvironment and malignant transformation.

\section{Evidence that breast implant ALCL is underdiagnosed}

Although there has been a substantial increase in recognition and awareness of breast implant ALCL over the last few years, we believe this disease is still likely underdiagnosed for several reasons:

a. No grossly identifiable mass/lesion in the resected specimen. In most cases, the removed breast implant is intact and the surrounding capsule has a discrete diffuse thickening, but usually not a distinct lesion, thus the specimen is misinterpreted and mishandled, usually leading to insufficient sampling. Furthermore, some institutions exempt breast capsules from histologic evaluation entirely, especially if there is no grossly identifiable lesion.

b. Imaging studies are not adequately sensitive to detect breast implant ALCL presenting with effusion, ranging from about $30 \%$ for mammography to $80 \%$ for ultrasound, 
Table 6 Criteria to distinguish a CD30+lymphoproliferative disorder from lymphoma

Table 7 Mimics of breast implant ALCL presenting with effusion or mass adjacent to breast implant

\begin{tabular}{lll}
\hline & Lymphoproliferative Disorder & Lymphoma \\
\hline Spontaneous Regression & Common & Rare \\
Architecture & Preserved & Destroyed \\
Cytology & Bland to anaplastic & Anaplastic \\
Immunophenotype & Preserved T-cell antigens & "Loss of T-cell antigens" \\
Clonality $(T R B, T R G)$ & Sometimes & Often \\
Karyotype & Diploid & Complex karyotype \\
\hline
\end{tabular}

\begin{tabular}{|c|c|c|c|}
\hline Disease entity & Reference & Clinical context & Evidence support \\
\hline \multicolumn{4}{|l|}{ Malignancies } \\
\hline Extranodal T/NK cell lymphoma & Aladily T et al [102] & Mass & EBER, CD56 \\
\hline Plasmablastic lymphoma & Unpublished & Mass & EBER, CD138 \\
\hline $\begin{array}{l}\text { HHV8 pos large B cell } \\
\text { lymphoma }\end{array}$ & Said JW et al [103] & Effusion & HHV8, EBER \\
\hline Diffuse large B-cell lymphoma & Messer A et al [104] & Effusion, mass & CD20, PAX5 \\
\hline Lymphoplasmacytic lymphoma & $\begin{array}{l}\text { Kraemer AM et al } \\
\text { [105] }\end{array}$ & Secondary & CD20, PAX5, IgM \\
\hline Follicular lymphoma & Cook PD et al [106] & Secondary, mass & CD20, BCL2 \\
\hline Breast cancer & $\begin{array}{l}\text { Roubaud MJ et al } \\
\text { [107] }\end{array}$ & Effusion & Cytokeratin \\
\hline Mycosis fungoides & Duvic M et al [108] & Skin lesions & $\mathrm{CD} 3, \mathrm{CD} 4$ \\
\hline \multicolumn{4}{|l|}{ Benign processes } \\
\hline Late seroma & Chai $\mathrm{M}$ et al [55] & Effusion & Benign cytology \\
\hline Hematoma & Mauro S et al [109] & $\begin{array}{l}\text { Blood clot, granulation } \\
\text { tissue }\end{array}$ & $\begin{array}{l}\text { Bland cytologic } \\
\text { features }\end{array}$ \\
\hline Implant rupture & Berry R et al $[110]$ & Silicone around implant & $\begin{array}{l}\text { Foreign body } \\
\text { reaction }\end{array}$ \\
\hline Siliconome & Lee $Y$ et al $[111]$ & Mass, lymphadenopathy & $\begin{array}{l}\text { Foreign body } \\
\text { reaction }\end{array}$ \\
\hline
\end{tabular}

and intermediate values for CT scan and PET scan [32]. Similar sensitivity was reported for the detection of breast implant ALCL presenting with a mass, although PET was more than $80 \%$ sensitive [1].

c. Cytological examination and flow cytometry are sensitive depending on the quality of the specimen. When breast implant ALCL is not suspected, and only a limited volume is sent for morphologic examination or flow cytometry immunophenotyping, there is a lower chance to identify a neoplastic population. (unpublished data)

d. Clinically, the diagnosis may not be suspected. With the presence of effusion, clinicians tend to initially consider a ruptured implant, infection, allergy or trauma. The rarity and appearance in only a select patient population makes it likely that many practicing physicians may not yet be fully aware of this complication of breast implants.

Breast implant ALCL also may be underdiagnosed because there is still some doubt that this disease represents a true lymphoma as some researchers consider breast implant ALCL as a clinically indolent lymphoproliferative disorder, amenable to spontaneous regression if left untouched. Some characteristics which may be helpful but not definitive in determining whether other CD30 positive lymphoproliferative disorders are benign or malignant are shown in Table 6. For pathologists, primary cutaneous CD30 positive lymphoproliferative disorders that may undergo spontaneous remission, come to mind because of its similarities with breast implant ALCL. In our experience, we have not observed cases of breast implant ALCL that regressed spontaneously, and we believe that if left untreated, the disease will remain or progress. We identified 11 patients with breast implant ALCL who had a history of effusion 0.4-3 years before the actual diagnosis (unpublished data). A review of the original specimens revealed diagnostic features of breast implant ALCL. On the other hand, Fleming et al. [51] published two cases of breast implant ALCL that they noted a decrease of the tumor burden in one case and undetectable tumor cells after fine needle aspiration drainage of the effusion. The authors claimed that patients had spontaneous regression and 


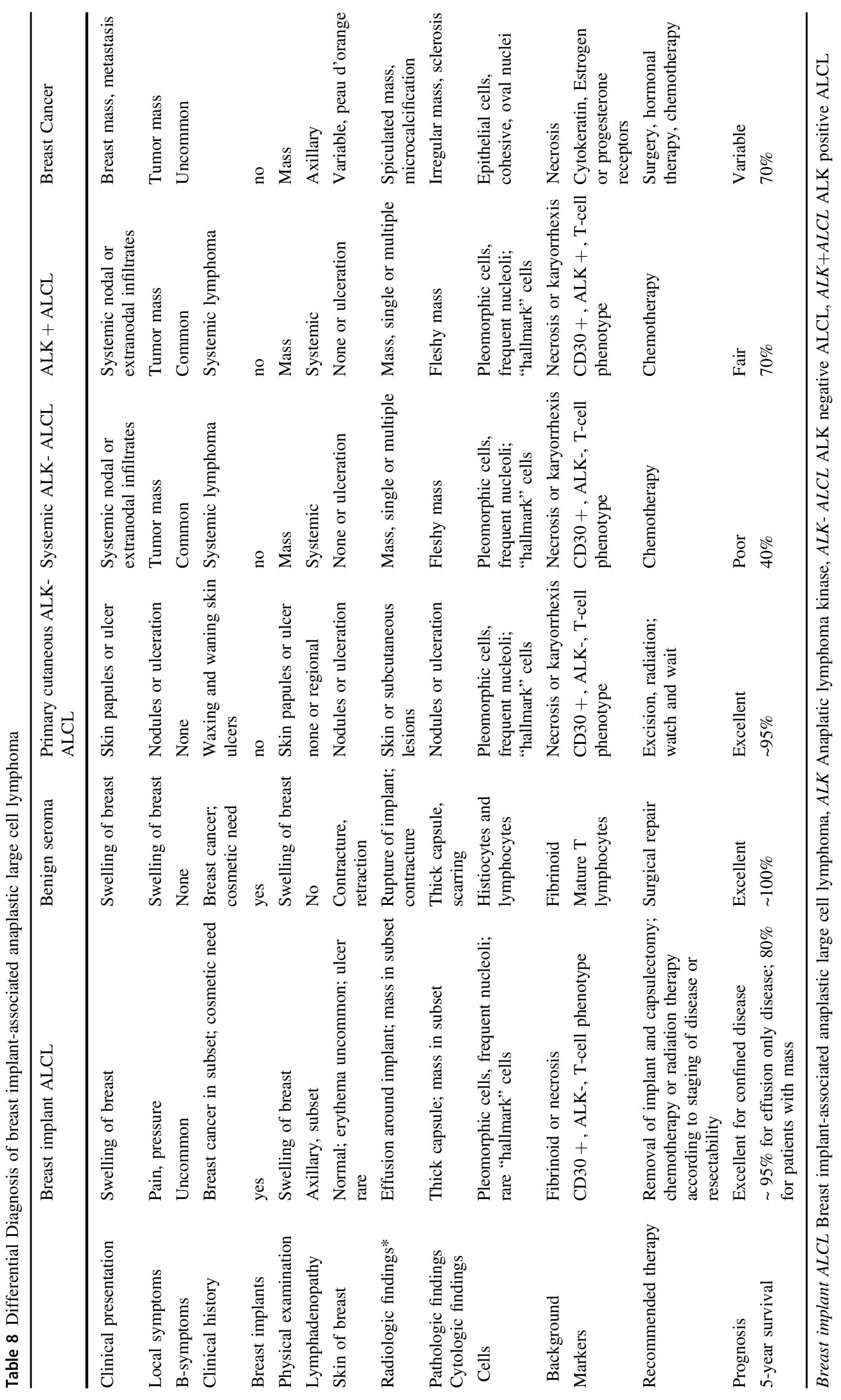




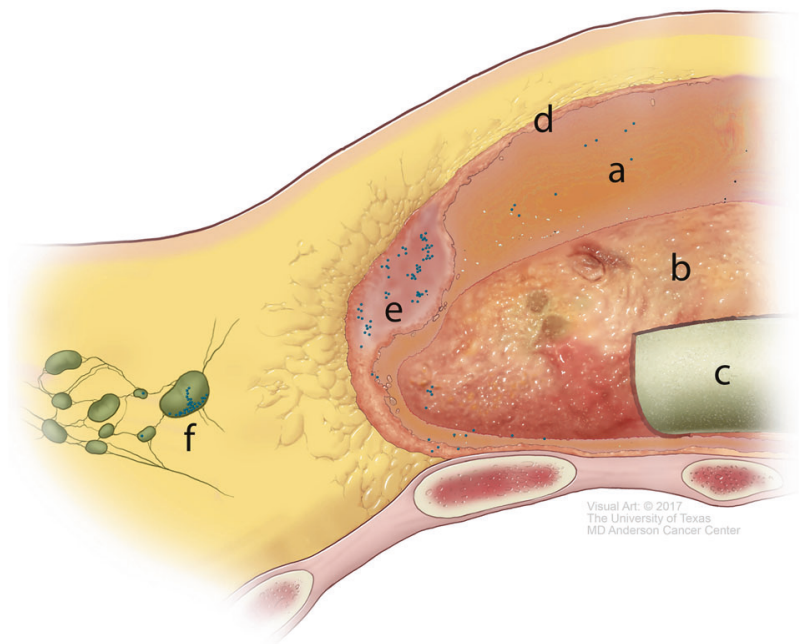

Fig. 10 Hypothesis of tumor progression of breast implant ALCL: a Breast implant ALCL arises as single cells surrounding a textured implant; proliferating cells initially manifest as necrotic effusion (improperly called seroma) around the implant. b Eventually cells attach to the luminal surface of the capsule. $\mathbf{c}$ The textured surface of the implant is usually intact albeit covered by a layer of fibrinonecrotic material. $\mathbf{d}$ The capsule progressively becomes thicker due to fibrosis, inflammatory cells, and lymphoma cell infiltration. e A mass detected clinically or by imaging studies indicates that the lymphoma cells have infiltrated beyond the capsule. f Approximately $20 \%$ of patients with breast implant ALCL have lymph node involvement

resolution of their tumors. However, upon careful scrutiny of these two cases [101] it was noted that both patients achieved long term complete remission, but within few months after diagnosis, they both had complete capsulectomy, a procedure that is considered curative for this lymphoma [34, 66].

There are instances of other malignancies [102] or benign processes that may mimic breast implant ALCL either because they present with effusion or a mass adjacent to breast capsule [103-111]. A list is displayed in Table 7. Furthermore, ALCL can present in other sites and secondarily in the breast. These possibilities are better considered in the differential diagnosis shown in Table 8. Benign effusions/seromas still represent the majority of cases of delayed effusion in patients with breast implants. Cytologically, specimens are paucicellular, consisting of small lymphocytes and histiocytes; sometimes the effusions are bloody. No large atypical cells are noted. Rare cases of breast implant ALCL can present as skin lesions in the breast region, and may be initially considered as primary cutaneous CD30 positive lymphoproliferative disorders (either primary cutaneous ALCL or lymphomatoid papulosis). The distinction is based on small size and waxing and waning lesions of lymphomatoid papulosis. The distinction from primary cutaneous ALCL can be impossible if the history of underlying breast implant ALCL is not known. Systemic ALCL rarely involves skin and less often can be localized to the breast. When noted in the breast of patients with implants, the lesion is not attached or in contact with the capsule of the implant. Breast cancer may be suspected in patients with implants placed for reconstruction, and any abnormal mass should raise the suspicion of recurrent carcinoma. A rare case of recurrent breast cancer was reported with effusion around the implant [107].

\section{A model of progression of breast implant ALCL}

An analysis of most published cases in the literature and our experience [3, 29, 31, 32, 34, 42, 50, 79], supports the theory of tumor progression. In particular, patients with breast implant ALCL confined to the luminal side of the capsule have a better event free survival and overall survival than patients with disease beyond the capsule [31], or patients with lymph node involvement [46]. Similarly, the reported cases of death have occurred in patients with disease beyond the capsule or patients with disseminated disease [28, 112]. A more refined analysis of the pathologic specimens shows cases with disease confined only to the effusion, cases with minimal of superficial infiltration of the capsule and cases with deeper infiltration of the capsule. Based on these observations, we proposed a pathologic staging published by Clemens et al. [34] that has been cited in subsequent peer-reviewed literature. Therefore, we believe that breast implant ALCL arises as single cells surrounding a textured implant that incites by still not fully elucidated mechanisms, cell growth and necrosis, initially manifesting as effusion (improperly called "seroma"). Since all cases in our series have a capsule around the implant and tumor cells are on the surface in contact with the implant (i.e., the luminal side) the differences between cases lie in the extent of involvement in the capsule, depth of invasion, and the most advanced cases have disease in both the luminal side and the outside of the capsule, i.e., tumor involvement of the surrounding breast parenchyma or soft tissue. A mass detected clinically or by imaging studies indicates that the tumor has infiltrated beyond the fibrous capsule. This infiltration is usually local into the chest wall and is associated with regional lymph node involvement [34]. (Fig. 10). Involvement of the mediastinal structures can lead to asphyxia and fatal outcome [28, 34]. Less commonly, systemic dissemination can occur $[112,113]$.

\section{Conclusions}

Breast implant ALCL is a distinct clinicopathological entity that is clearly different from systemic ALCL, both ALK+ 
and ALK-, as well as from primary cutaneous ALCL. Although rare, we predict that with increased awareness among clinicians and pathologists the number of cases will continue to increase, as we have witnessed since its original description nearly 20 years ago. Breast implants have been deemed safe and approved by regulatory agencies in many countries. The number of reconstructive and cosmetic breast implants will likely continue to grow worldwide, increasing the likelihood that more cases will be diagnosed. With increased awareness, a tumor global registry will be highly desirable to better monitor the long-term course of the disease.

\section{Compliance with ethical standards}

Conflict of interest Roberto N. Miranda has attended a 1-day Allergan Inc. sponsored meeting as an advisory scientific expert. This activity was authorized by the legal department at MD Anderson Cancer Center. The current review article is sponsored only and exclusively by the Department of Hematopathology at The University of Texas MD Anderson Cancer Center.

\section{References}

1. Keech JA Jr, Creech BJ. Anaplastic T-cell lymphoma in proximity to a saline-filled breast implant. Plast Reconstr Surg. 1997;100:554-5.

2. Roden AC, Macon WR, Keeney GL, et al. Seroma-associated primary anaplastic large-cell lymphoma adjacent to breast implants: an indolent T-cell lymphoproliferative disorder. Mod Pathol. 2008;21:455-63.

3. Feldman AL, Harris NL, Stein H, et al. Breast implant-associated anaplastic large cell lymphoma. In: Swerdlow SH, Campo E, Harris NL, Jaffe ES, Pileri SA, Stein H, Thiele J, (Eds). WHO classification of tumours of haematopoietic and lymphoid tissues (Revised. 4th ed. Lyon: IARC; 2017.

4. FDA. Anaplastic Large Cell Lymphoma (ALCL) in Women with Breast Implants: Preliminary FDA Findings and Analyses. http://www.fda.gov/MedicalDevices/ProductsandMedicalProcedures/ ImplantsandProsthetics/BreastImplants/ (2011). Accessed 20 Nov 2014.

5. Clemens MW BIA-ALCL Physician Resources. https://www.pla sticsurgery.org/for-medical-professionals/health-policy/bia-alclphysician-resources (2018). Accessed 28 May 2018.

6. Yoshida SH, Swan S, Teuber SS, Gershwin ME. Silicone breast implants: immunotoxic and epidemiologic issues. Life Sci. 1995;56:1299-310.

7. Kessler DA. The basis of the FDA's decision on breast implants. N Engl J Med. 1992;326:1713-5.

8. Cruz NI. Current status of silicone breast implants. Bol Asoc Med P R. 1991;83:326-8.

9. Fock KM, Feng PH, Tey BH. Autoimmune disease developing after augmentation mammoplasty: report of 3 cases. J Rheumatol. $1984 ; 11: 98-100$.

10. Spiera H. Scleroderma after silicone augmentation mammoplasty. JAMA. 1988;260:236-8.

11. Spiera H, Kerr LD. Scleroderma following silicone implantation: a cumulative experience of 11 cases. J Rheumatol. 1993;20:958-61.
12. Okano Y, Nishikai M, Sato A. Scleroderma, primary biliary cirrhosis, and Sjogren's syndrome after cosmetic breast augmentation with silicone injection: a case report of possible human adjuvant disease. Ann Rheum Dis. 1984;43:520-2.

13. Weiner SR, Paulus HE. Chronic arthropathy occurring after augmentation mammaplasty. Plast Reconstr Surg. 1986;77:185-92.

14. Sergott TJ, Limoli JP, Baldwin CM Jr., Laub DR. Human adjuvant disease, possible autoimmune disease after silicone implantation: a review of the literature, case studies, and speculation for the future. Plast Reconstr Surg. 1986;78:104-14.

15. Varga J, Schumacher HR, Jimenez SA. Systemic sclerosis after augmentation mammoplasty with silicone implants. Ann Intern Med. 1989;111:377-83.

16. Sahn EE, Garen PD, Silver RM, Maize JC. Scleroderma following augmentation mammoplasty. Report of a case and review of the literature. Arch Dermatol. 1990;126:1198-202.

17. Tugwell P, Wells G, Peterson J, et al. Do silicone breast implants cause rheumatologic disorders? A systematic review for a courtappointed national science panel. Arthritis Rheum. 2001;44:2477-84.

18. Wong O. A critical assessment of the relationship between silicone breast implants and connective tissue diseases. Regul Toxicol Pharmacol. 1996;23:74-85.

19. Perkins LL, Clark BD, Klein PJ, Cook RR. A meta-analysis of breast implants and connective tissue disease. Ann Plast Surg. 1995;35:561-70.

20. Brody GS. On the safety of breast implants. Plast Reconstr Surg. 1997;100:1314-21.

21. Nosanchuk JS. Injected dimethylpolysiloxane fluid: a study of antibody and histologic response. Plast Reconstr Surg. 1968;42:562-6

22. Clemens MW, Miranda RN, Butler CE. Breast implant informed consent should include the risk of anaplastic large cell lymphoma. Plast Reconstr Surg. 2016;137:1117-22.

23. van Diest PJ, Beekman WH, Hage JJ. Pathology of silicone leakage from breast implants. J Clin Pathol. 1998;51:493-7.

24. Pittet B, Montandon D, Pittet D. Infection in breast implants. Lancet Infect Dis. 2005;5:94-106.

25. Tarpila E, Ghassemifar R, Fagrell D, Berggren A. Capsular contracture with textured versus smooth saline-filled implants for breast augmentation: a prospective clinical study. Plast Reconstr Surg. 1997;99:1934-9.

26. Talwalkar SS, Miranda RN, Valbuena JR, et al. Lymphomas involving the breast: a study of 106 cases comparing localized and disseminated neoplasms. Am J Surg Pathol. 2008;32:1299-309.

27. de Jong D, Vasmel WL, de Boer JP, et al. Anaplastic large-cell lymphoma in women with breast implants. JAMA. 2008;300:2030-5.

28. Carty MJ, Pribaz JJ, Antin JH, et al. A patient death attributable to implant-related primary anaplastic large cell lymphoma of the breast. Plast Reconstr Surg. 2011;128:112e-8e.

29. Aladily TN, Medeiros LJ, Amin MB, et al. Anaplastic large cell lymphoma associated with breast implants: a report of 13 cases. Am J Surg Pathol. 2012;36:1000-8.

30. Lechner MG, Megiel C, Church $\mathrm{CH}$, et al. Survival signals and targets for therapy in breast implant-associated ALK--anaplastic large cell lymphoma. Clin Cancer Res. 2012;18:4549-59.

31. Miranda RN, Aladily TN, Prince HM, et al. Breast implantassociated anaplastic large-cell lymphoma: long-term follow-up of 60 patients. J Clin Oncol. 2014;32:114-20.

32. Adrada BE, Miranda RN, Rauch GM, et al. Breast implantassociated anaplastic large cell lymphoma: sensitivity, specificity, and findings of imaging studies in 44 patients. Breast Cancer Res Treat. 2014;147:1-14. 
33. Hu H, Johani K, Almatroudi A, et al. Bacterial biofilm infection detected in breast implant-associated anaplastic large-cell lymphoma. Plast Reconstr Surg. 2016;137:1659-69.

34. Clemens MW, Medeiros LJ, Butler CE, et al. Complete surgical excision is essential for the management of patients with breast implant-associated anaplastic large-cell lymphoma. J Clin Oncol. 2016;34:160-8.

35. Wang SS, Deapen D, Voutsinas J, et al. Breast implants and anaplastic large cell lymphomas among females in the California Teachers Study cohort. Br J Haematol. 2016;174:480-3.

36. Doren EL, Miranda RN, Selber JC, et al. U.S. epidemiology of breast implant-associated anaplastic large cell lymphoma. Plast Reconstr Surg. 2017;139:1042-50.

37. de Boer M, van Leeuwen FE, Hauptmann M, et al. Breast Implants and the risk of anaplastic large-cell lymphoma in the breast. JAMA Oncol. 2018;4:335-341.

38. Oishi N, Brody G, Ketterling R, et al. Genetic subtyping of breast implant-associated anaplastic large cell lymphoma. Blood. 2018;132:544-547.

39. Brody GS, Deapen D, Taylor CR, et al. Anaplastic large cell lymphoma occurring in women with breast implants: analysis of 173 cases. Plast Reconstr Surg. 2015;135:695-705.

40. Lipworth L, Tarone RE, McLaughlin JK. Breast implants and lymphoma risk: a review of the epidemiologic evidence through 2008. Plast Reconstr Surg. 2009;123:790-3.

41. Largent J, Oefelein M, Kaplan HM, Okerson T, Boyle P. Risk of lymphoma in women with breast implants: analysis of clinical studies. Eur J Cancer Prev: Off J Eur Cancer Prev Organ. 2012;21:274-80.

42. Thompson PA, Lade S, Webster H, Ryan G, Prince HM. Effusion-associated anaplastic large cell lymphoma of the breast: time for it to be defined as a distinct clinico-pathological entity. Haematologica. 2010;95:1977-9.

43. FDA. Breast implant-associated anaplastic large cell lymphoma (BIA-ALCL). https://www.fda.gov/MedicalDevices/Productsa ndMedicalProcedures/ImplantsandProsthetics/BreastImplants/ ucm239995.htm (2018). Accessed 24 Mar 2018.

44. Clemens MW. Discussion: anaplastic large cell lymphoma in the plastic surgery practice: has it influenced practice patterns? Plast Reconstr Surg. 2016;138:819e-20e.

45. Laurent C, Delas A, Gaulard P, et al. Breast implant-associated anaplastic large cell lymphoma: two distinct clinicopathological variants with different outcomes. Ann Oncol. 2016;27: 306-14.

46. Ferrufino-Schmidt MC, Medeiros LJ, Liu H, et al. Clinicopathologic features and prognostic impact of lymph node involvement in patients with breast implant-associated anaplastic large cell lymphoma. Am J Surg Pathol. 2018;42:293-305.

47. Miranda RN, Medeiros LJ. Breast implant-associated anaplastic large cell lymphoma. In: Medeiros LJ, Miranda RN, (ed). Diagnostic pathology: lymph nodes and extranodal lymphomas. 2nd ed. Salt Lake City, UT: Elsevier; 2017. p. 634-43.

48. Alobeid B, Sevilla DW, El-Tamer MB, et al. Aggressive presentation of breast implant-associated ALK-1 negative anaplastic large cell lymphoma with bilateral axillary lymph node involvement. Leuk Lymphoma. 2009;50:831-3.

49. Spear SL, Rottman SJ, Glicksman C, Brown M, Al-Attar A. Late seromas after breast implants: theory and practice. Plast Reconstr Surg. 2012;130:423-35.

50. Brody GS. Brief recommendations for dealing with a new case of anaplastic large T-cell lymphoma. Plast Reconstr Surg. 2012;129:871e-2e.

51. Fleming D, Stone J, Tansley P. Spontaneous regression and resolution of breast implant-associated anaplastic large cell lymphoma: implications for research, diagnosis and clinical management. Aesthetic Plast Surg. 2018;42:672-678.
52. Anonym. Revised CAP guidelines for prosthetic breast implants. In: CAP today. Vol. 9. Chicago: College of American Pathologists; 1995.

53. Zarbo RJ, Nakhleh RE. Surgical pathology specimens for gross examination only and exempt from submission: a College of American Pathologists Q-Probes study of current policies in 413 institutions. Arch Pathol Lab Med. 1999;123:133-9.

54. Bautista-Quach MA, Nademanee A, Weisenburger DD, Chen W, Kim YS. Implant-associated primary anaplastic large-cell lymphoma with simultaneous involvement of bilateral breast capsules. Clin Breast Cancer. 2013;13:492-5.

55. Chai SM, Kavangh S, Ooi SS, et al. Anaplastic large-cell lymphoma associated with breast implants: a unique entity within the spectrum of peri-implant effusions. Diagn Cytopathol. 2014;42:929-38.

56. De Silva IM, Teague JA, Blake WE. Breast implant associated anaplastic large cell lymphoma: a case report and reconstructive option. J Plast Reconstr Aesthet Surg. 2013;66:1773-6.

57. Farace F, Bulla A, Marongiu F, et al. Anaplastic large cell lymphoma of the breast arising around mammary implant capsule: an Italian report. Aesthetic Plast Surg. 2013;37:567-71.

58. Ivaldi C, Perchenet AS, Jallut Y, Casanova D. Two cases of lymphoma in an implant capsule: a difficult diagnosis, an unknown pathology. Ann Chir Plast Esthet. 2013;58:688-93.

59. Miranda RN, Lin L, Talwalkar SS, Manning JT, Medeiros LJ. Anaplastic large cell lymphoma involving the breast: a clinicopathologic study of 6 cases and review of the literature. Arch Pathol Lab Med. 2009;133:1383-90.

60. Farkash EA, Ferry JA, Harris NL, et al. Rare lymphoid malignancies of the breast: a report of two cases illustrating potential diagnostic pitfalls. J Hematop. 2009;2:237-44.

61. Newman MK, Zemmel NJ, Bandak AZ, Kaplan BJ. Primary breast lymphoma in a patient with silicone breast implants: a case report and review of the literature. J Plast Reconstr Aesthet Surg. 2008;61:822-5.

62. Olack B, Gupta R, Brooks GS. Anaplastic large cell lymphoma arising in a saline breast implant capsule after tissue expander breast reconstruction. Ann Plast Surg. 2007;59:56-7.

63. Popplewell L, Thomas SH, Huang Q, Chang KL, Forman SJ. Primary anaplastic large-cell lymphoma associated with breast implants. Leuk Lymphoma. 2011;52:1481-7.

64. Smith TJ, Ramsaroop R. Breast implant related Anaplastic Large Cell Lymphoma presenting as late onset peri-implant effusion. Breast. 2012;21:102-4.

65. Talagas M, Uguen A, Charles-Petillon F, et al. Breast implantassociated anaplastic large-cell lymphoma can be a diagnostic challenge for pathologists. Acta Cytol. 2014;58:103-7.

66. Clemens MW, Horwitz SM.NCCN consensus guidelines for the diagnosis and management of breast implant-associated anaplastic large cell lymphoma.Aesthetic Surg J/Am Soc Aesthetic Plast Surg. 2017;37:285-9.

67. Chourmouzi DVT, Drevelegas A. New spontaneous breast seroma 5 years after augmentation: a case report. Cases J. 2009;2:7126.

68. Mazzocchi MDL, Corrias F, Scuderi N. A clinical study of late seroma in breast implantation surgery. Aesthetic Plast Surg. 2012;36:97-104.

69. Murphy S, Carroll S. Importance of histological analysis of seroma fluid. Aesthetic Plast Surg. 2013;37:187-8.

70. George EV, Pharm J, Houston C, et al. Breast implant-associated ALK-negative anaplastic large cell lymphoma: a case report and discussion of possible pathogenesis. Int $\mathrm{J}$ Clin Exp Pathol. 2013;6:1631-42.

71. Singh E, Frost E, Morris EJ, Raza S. Anaplastic lymphoma masquerading as breast abscess in a patient with silicone implants. Breast J. 2013;19:543-5. 
72. Li S, Lee AK. Silicone implant and primary breast ALK1negative anaplastic large cell lymphoma, fact or fiction? Int $\mathrm{J}$ Clin Exp Pathol. 2009;3:117-27.

73. Weathers WM, Wolfswinkel EM, Hatef DA, et al. Implantassociated anaplastic large cell lymphoma of the breast: Insight into a poorly understood disease. Can J Plast Surg. 2013;21:95-8.

74. Taylor CR, Siddiqi IN, Brody GS. Anaplastic large cell lymphoma occurring in association with breast implants: review of pathologic and immunohistochemical features in 103 cases. Appl Immunohistochem Mol Morphol. 2013;21:13-20.

75. Lechner MG, Lade S, Liebertz DJ, et al. Breast implant-associated, ALK-negative, T-cell, anaplastic, large-cell lymphoma: establishment and characterization of a model cell line (TLBR-1) for this newly emerging clinical entity. Cancer. 2011;117:1478-89.

76. Hart AM, Lechowicz MJ, Peters KK, Holden J, Carlson GW. Breast implant-associated anaplastic large cell lymphoma: report of 2 cases and review of the literature. Aesthetic Surg J/Am Soc Aesthetic Plast Surg. 2014;34:884-94.

77. Feldman AL, Dogan A, Smith DI, et al. Discovery of recurrent $t$ $(6 ; 7)(\mathrm{p} 25.3 ; \mathrm{q} 32.3)$ translocations in ALK-negative anaplastic large cell lymphomas by massively parallel genomic sequencing. Blood. 2011;117:915-9.

78. Vasmatzis G, Johnson SH, Knudson RA, et al. Genome-wide analysis reveals recurrent structural abnormalities of TP63 and other p53-related genes in peripheral T-cell lymphomas. Blood. 2012;120:2280-9.

79. Story SK, Schowalter MK, Geskin LJ. Breast implant-associated ALCL: a unique entity in the spectrum of CD30+lymphoproliferative disorders. Oncologist. 2013;18:301-7.

80. Talmadge JE, Donkor M, Scholar E. Inflammatory cell infiltration of tumors: Jekyll or Hyde. Cancer Metastas- Rev. 2007;26:373-400.

81. Malcolm TI, Hodson DJ, Macintyre EA, Turner SD. Challenging perspectives on the cellular origins of lymphoma. Open Biol 2016;6.

82. Multhoff G, Molls M, Radons J. Chronic inflammation in cancer development. Front Immunol. 2011;2:98.

83. Rauch D, Gross S, Harding J, et al. T-cell activation promotes tumorigenesis in inflammation-associated cancer. Retrovirology. 2009;6:116.

84. Bondurant S, Ernster V, Herdman R. Safety of silicone breast implants. National Academies Press. Washington, D.C.; 2000.

85. Lazzeri D, Agostini T, Bocci G, et al. ALK-1-negative anaplastic large cell lymphoma associated with breast implants: a new clinical entity. Clin Breast Cancer. 2011;11:283-96.

86. Meza Britez ME, Caballero Llano C, Chaux A. Periprosthetic breast capsules and immunophenotypes of inflammatory cells. Eur J Plast Surg. 2012;35:647-51.

87. Xu S, Cao X. Interleukin-17 and its expanding biological functions. Cell Mol Immunol. 2010;7:164-74.

88. Wolfram D, Rabensteiner E, Grundtman C, et al. T regulatory cells and TH17 cells in peri-silicone implant capsular fibrosis. Plast Reconstr Surg. 2012;129:327e-37e.

89. Leung S, Liu X, Fang L, et al. The cytokine milieu in the interplay of pathogenic Th1/Th17 cells and regulatory T cells in autoimmune disease. Cell Mol Immunol. 2010;7:182-9.

90. Kadin ME, Morgan J, Xu H, et al. IL-13 is produced by tumor cells in Breast Implant Associated Anaplastic Large Cell Lymphoma: implications for pathogenesis. Hum Pathol. 2018;78:54-62.

91. Kadin ME, Deva A, Xu H, et al. Biomarkers Provide Clues to Early Events in the Pathogenesis of Breast Implant-Associated Anaplastic Large Cell Lymphoma. Aesthetic Surg J/Am Soc Aesthetic Plast Surg. 2016;36:773-81.
92. Adams WP Jr., Culbertson EJ, Deva AK, et al. Macrotextured breast implants with defined steps to minimize bacterial contamination around the device: experience in 42,000 implants. Plast Reconstr Surg. 2017;140:427-31.

93. Johnson L, O'Donoghue JM, McLean N, et al. Breast implant associated anaplastic large cell lymphoma: the UK experience. Recommendations on its management and implications for informed consent. Eur J Surg Oncol. 2017;43:1393-401.

94. Gidengil CA, Predmore Z, Mattke S, van Busum K, Kim B. Breast implant-associated anaplastic large cell lymphoma: a systematic review. Plast Reconstr Surg. 2015;135:713-20.

95. McGuire P, Reisman NR, Murphy DK. Risk factor analysis for capsular contracture, malposition, and late seroma in subjects receiving natrelle 410 form-stable silicone breast implants. Plast Reconstr Surg. 2017;139:1-9.

96. Clemens MW. Discussion: breast implant-associated anaplastic large cell lymphoma in Australia and New Zealand: highsurface-area textured implants are associated with increased risk. Plast Reconstr Surg. 2017;140:660-2.

97. Hofler M. The Bradford Hill considerations on causality: a counterfactual perspective. Emerg Themes Epidemiol. 2005;2:11.

98. Hill AB. The environment and disease: association or causation? 1965. J R Soc Med. 2015;108:32-7.

99. Chan JKC, Aozasa K, Gaulard P. Diffuse large B-cell lymphoma associated with chronic inflammation. In: Swerdlow SH, Campo E, Harris NH, et al. (eds). WHO classification of tumours of the haematopoietic and lymphoid tissues. Revised 4th edn. Lyon: IARC; 2017. p. 309-11.

100. Aguilar C, Beltran B, Quinones P, et al. Large B-cell lymphoma arising in cardiac myxoma or intracardiac fibrinous mass: a localized lymphoma usually associated with Epstein-Barr virus? Cardiovascular pathology: the official journal of the Society for. Cardiovasc Pathol. 2015;24:60-4.

101. Magnusson MR, Deva AK. Letter toEditor: Fleming D, Stone J, Tansley $\mathrm{P}$ spontaneous regression and resolution of breast implant-associated anaplastic large cell lymphoma: implications for research, diagnosis and clinical management, APS 2018. Aesthetic Plast Surg. 2018;42:1164-1166.

102. Aladily TN, Nathwani BN, Miranda RN, et al. Extranodal NK/ T-cell lymphoma, nasal type, arising in association with saline breast implant: expanding the spectrum of breast implant-associated lymphomas. Am J Surg Pathol. 2012; 36:1729-34.

103. Said JW, Tasaka T, Takeuchi S, et al. Primary effusion lymphoma in women: report of two cases of Kaposi's sarcoma herpes virus-associated effusion-based lymphoma in human immunodeficiency virus-negative women. Blood. 1996;88:3124-8.

104. Messer A, Jenkinson H, Wang W, Duvic M. New B-cell lymphomas in the setting of a previous rare breast implant-associated B-cell lymphoma. Plast Reconstr Surg Glob Open. 2016;4: e1148.

105. Kraemer DM, Tony HP, Gattenlohner S, Muller JG. Lymphoplasmacytic lymphoma in a patient with leaking silicone implant. Haematologica. 2004;89:ELT01.

106. Cook PD, Osborne BM, Connor RL, Strauss JF. Follicular lymphoma adjacent to foreign body granulomatous inflammation and fibrosis surrounding silicone breast prosthesis. Am J Surg Pathol. 1995;19:712-7.

107. Roubaud MJ, Kulber DA. A malignant late seroma 20 years after breast cancer and saline implants. Plast Reconstr Surg. 2013;131:655e-7e.

108. Duvic M, Moore D, Menter A, Vonderheid EC. Cutaneous T-cell lymphoma in association with silicone breast implants. J Am Acad Dermatol. 1995;32:939-42. 
109. Mauro S, Eugenio F, Roberto B. Late recurrent capsular hematoma after augmentation mammaplasty: case report. Aesthetic Plast Surg. 2005;29:10-2.

110. Berry RB. Rupture of PIP breast implants. J Plast Reconstr Aesthet Surg. 2007;60:967-8.

111. Lee Y, Song SE, Yoon ES, Bae JW, Jung SP. Extensive silicone lymphadenopathy after breast implant insertion mimicking malignant lymphadenopathy. Ann Surg Treat Res. 2017;93:331-5.
112. Zimmerman A, Locke FL, Emole J, et al. Recurrent systemic anaplastic lymphoma kinase-negative anaplastic large cell lymphoma presenting as a breast implant-associated lesion. Cancer Control. 2015;22:369-73.

113. Loghavi S, Medeiros LJ, Javadi S, et al. Breast implantassociated anaplastic large cell lymphoma with bone marrow involvement. Aesthetic surgery Journal/the Am Soc Aesthetic Plastic Surg 2018;38: NP92-NP96. 